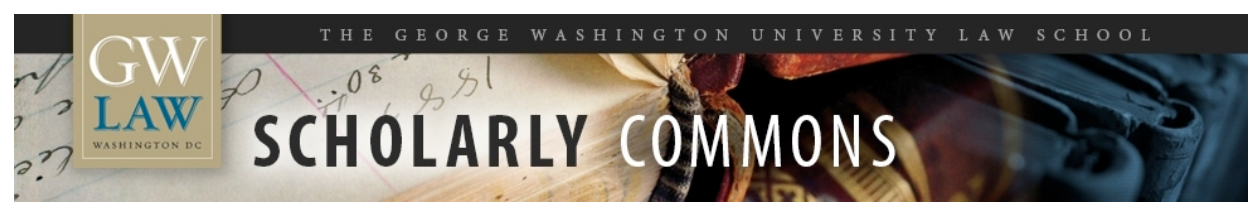

\title{
Why Who Does What Matters: Governmental Design, Agency Performance, the CFPB and PPACA
}

William E. Kovacic

George Washington University Law School, wkovacic@law.gwu.edu

Follow this and additional works at: https://scholarship.law.gwu.edu/faculty_publications

Part of the Law Commons

\section{Recommended Citation}

Illinois Program in Law, Behavior and Social Science Paper No. LBSS14-11

This Article is brought to you for free and open access by the Faculty Scholarship at Scholarly Commons. It has been accepted for inclusion in GW Law Faculty Publications \& Other Works by an authorized administrator of Scholarly Commons. For more information, please contact spagel@law.gwu.edu. 


\title{
Why Who Does What Matters: Governmental Design, Agency Performance, the CFPB and PPACA
}

\author{
David A. Hyman \& William E. Kovacic ${ }^{1}$
}

\begin{abstract}
How should the federal government be organized - and who (i.e., which departments, agencies, bureaus, and commissions) should do what? The issue is not new: President James Madison addressed governmental organization in his 1812 State of the Union Address, and in the last century, it is the rare President that does not propose to reorganize some part of the federal government. Indeed, on numerous occasions during the past century, virtually every part of the federal government has been repeatedly reorganized and reconfigured. In previous work, we examined the dynamics that influence the assignment of regulatory duties to an agency, how those dynamics (and the allocation of responsibilities) can change over time, and how the specific combination of regulatory functions and purposes affect agency decision-making. In this article, we focus on the Consumer Financial Protection Bureau ("CFPB"). Using the framework we developed in our previous work, we examine the costs and benefits of the design choices made by the architects of the CFPB, and make some (appropriately hedged) predictions about the future prospects of this latest addition to the federal bureaucracy. We also briefly consider the implications of our analysis for the implementation of the Patient Protection and Affordable Care Act ("PPACA").
\end{abstract}

\footnotetext{
${ }^{1}$ Hyman is H. Ross \& Helen Workman Chair in Law and Professor of Medicine, University of Illinois. From 2001-2004, he served as Special Counsel at the Federal Trade Commission. Kovacic is Professor at the George Washington University School of Law. From 2001-2011, he was, at various points, the General Counsel, Commissioner, and Chairman of the Federal Trade Commission.

The authors are grateful for the comments of participants in workshops at the Australia and New Zealand School of Government, Case Western Reserve Law School, the Financial Services section of the Association of American Law Schools 2011 Annual Meeting, Duke University, Oxford University, and the University of Michigan, the University of Pennsylvania, and University of Illinois Law Schools. We are also grateful for the written comments we received from Jud Matthews, Arden Rowell, Danny Sokol, and Melissa Wasserman.

The analytical framework we present in this article was presented in earlier form in David A. Hyman \& William E. Kovacic, Competition Agencies with Complex Policy Portfolios: Divide or Conquer? 2013 Concurrences, available at http://www.concurrences.com/Journal/Issues/No-1-2013/Articles/Competition-agencieswith-complex.
} 
We live and do business in the Information Age, but the last major reorganization of the government happened in the age of black-and-white TV. There are 12 different agencies that deal with exports. There are at least five different agencies that deal with housing policy. Then there's my favorite example: The Interior Department is in charge of salmon while they're in fresh water, but the Commerce Department handles them when they're in saltwater. I hear it gets even more complicated once they're smoked.

President Barack Obama (2011)

There are four different kinds of bears in the United States, and, of course, all these bears come under the jurisdiction of one Government department or another. I think it is the brown bear that comes under the jurisdiction of the Department of the Interior, and I think the black bear comes under the Department of Agriculture; and the Alaska bear comes under the Department of Commerce; and jurisdiction over the grizzly bear is held by the Department of War. That has been going on from time immemorial in Washington. Each bear - the care of the bear and everything else about the bear - falls under a different department, depending on the genus of the bear. And I am told confidentially that sometimes there is a most awful mixup, because sometimes a black bear falls in love with a brown bear, and then nobody knows under what department the puppies belong.

\section{President Franklin D. Roosevelt $(1928)^{3}$}

If we shouldn't have twelve agencies dealing with exports, and five agencies dealing with housing policy, and two departments dealing with salmon, and four agencies dealing with bears, then how many agencies and departments (and which ones) should be responsible for exports, housing, salmon, and bears? Does it really matter whether salmon are the sole responsibility of the Department of Interior (Fish \& Wildlife Service) or the

\footnotetext{
2 President Barack Obama, State of the Union Address, Jan. 25, 2011, at http://www.whitehouse.gov/the-press-office/2011/01/25/remarks-president-state-unionaddress

${ }^{3}$ Franklin Delano Roosevelt, Extemporaneous Campaign Address, Binghamton, N.Y., Oct. 17, 1928, available at 1 Public Papers and Addresses of Franklin D. Roosevelt 16 (1938).
} 
Department of Commerce (National Oceanic and Atmospheric Administration ("NOAA"))? What difference would it make if Interior and Commerce were stripped of responsibility for salmon, and sole authority was assigned to the Food \& Drug Administration (currently responsible for salmon once it is packaged) or the Department of Agriculture (which is responsible for catfish)? And, while we're at it, why is NOAA in the Department of Commerce, and why is regulatory authority over catfish in the Department of Agriculture? More broadly, even if these particular allocations of responsibility are not optimal, might there be some utility in shared or overlapping authority/responsibility - and if so, under what circumstances?

These issues are policy perennials. ${ }^{4}$ President James Madison addressed governmental organization in his 1812 State of the Union Address, ${ }^{5}$ and over the course of the last century, it is the rare President that does not propose to reorganize at least some part of the federal government. $^{67}$

${ }^{4}$ Cf. Gary L. Wamsley, et al. Bureaucracy in Democratic Governance, 80-81 in THE STATE OF PUblic BUREAUCRACY, Larry B. Hill, ed. (1992) (observing that reorganization is the "cod liver oil of government--an all purpose cure for whatever ails the body politic.")

${ }^{5}$ President James Madison, State of the Union Address, Nov. 4, 1812, at http://www.infoplease.com/t/hist/state-of-the-union/24.html ("I can not press too strongly on the earliest attention of the Legislature the importance of the reorganization of the staff [military] establishment with a view to render more distinct and definite the relations and responsibilities of its several departments. That there is room for improvements which will materially promote both economy and success in what appertains to the Army and the war is equally inculcated by the examples of other countries and by the experience of our own.")

${ }^{6}$ Peri E. Arnold, Reforms Changing Role, 55 PuB. Admin. L. Rev. (1995) ("President Clinton is the thirteenth president in this century to initiate or embrace comprehensive reorganization or reform, using those terms interchangeably.") See also Peri E. Arnold, Making the Managerial Presidency: Comprehensive Reorganization Planning, 1905-1996 (University Press of Kansas, 1998).

More specifically, President Franklin Roosevelt conducted a bruising multi-year fight to reorganize the federal government, culminating with the creation of the Federal Security Agency. President Truman oversaw the unification of the Department of the Navy and the Department of War under a single Department of Defense in 1949. President Johnson oversaw the creation of the Departments of Housing and Urban Development and Transportation. President Nixon proposed to reorganize seven departments (Agriculture, Commerce, Health, Education \& Welfare, Housing \& Urban Development, Interior, and Labor) into four super-departments organized along functional lines (Community Development, Economic Resources, Human Resources, and Natural Resources), and was responsible for the creation of the Environmental Protection Agency. President Carter oversaw the creation of the Departments of Energy and Education, and also proposed two additional Departments - a Department of Development Assistance, and a Department of Natural Resources. President George W. Bush oversaw the merger of components of twenty-two separate agencies into the Department of Homeland Security ("DHS") -- which 
President Obama called for governmental reorganization in both the 2011 and 2012 State of the Union Addresses, and recently proposed the creation of a single cabinet-level department responsible for "boosting American business and promoting competitiveness." 8 President Obama also oversaw the enactment of the Dodd-Frank Wall Street Reform and Consumer Protection Act ("Dodd-Frank") in 2010, which shuttered one agency (the Office of Thrift Supervision ("OTS")) and merged its functions into the Office of the Comptroller of the Currency, and created a new bureau within the Federal Reserve (the Consumer Financial Protection Bureau ("CFPB")). ${ }^{9}$

Reorganization has also figured in presidential campaigns and primaries. President Carter ran on a platform of reorganizing government. And, during the 2012 presidential primaries, four of the Republican candidates promised to "reorganize" parts of the federal government. Governor Rick Perry committed to eliminate three cabinet-level departments, but memorably could only come up with two departments (Education and Commerce) when asked during a November, 2011 debate. $^{10}$ Representatives Newt Gingrich and Michele Bachman both promised to shutter the EPA. ${ }^{11}$ Representative Ron Paul wanted to close five federal departments: Education, Commerce, Energy, Interior and Housing and Urban Development. ${ }^{12}$

To summarize, on numerous occasions during the past century, virtually every part of the federal government has been reorganized and reconfigured. In the process, entire departments, agencies, bureaus and commissions have been created, moved, consolidated, divided, turned

was itself reorganized two years later. For details, see generally THE EXECUTIVE BRANCH (Joel D. ABERBACH \& MARK A. PETERSON, EDS. (2005).

${ }^{7} \mathrm{http}: / /$ www.dhs.gov/xabout/history/editorial 0133.shtm

8 Matt Compton, Making It Easier to Do Business in America, http://www.whitehouse.gov/blog/2012/01/13/making-it-easier-do-business-america; Mark Landler, Obama to Ask Congress for Power to Merge Agencies, N.Y. Times A1 (Jan. 13, 2012); Binyamin Applebaum \& Helene Cooper, White House Debates Fight on Economy, N.Y. Times A1 (Aug. 13, 2011).

${ }^{9} \mathrm{http} / / / \mathrm{www}$.onwallstreet.com/news/ots-bowman-dodd-frank-2669814-1.html

${ }^{10}$ Ed O'Keefe, What Do The Departments of Commerce, Education and Energy think of Rick Perry's plan? WASH POST FEDERAL EYE, Nov. 10, 2011 at http://www.washingtonpost.com/blogs/federal-eye/post/what-do-the-departments-ofcommerce-education-and-energy-think-of-rick-perrysplan/2011/11/10/gIQAXiSe8M blog.html. See also Mark Schmitt, Let's Get Real, No One's Eliminating Any Cabinet Departments, New REPublic, Nov. 11, 2011, at http://www.tnr.com/article/politics/97327/perry-debate-oops-cabinet-energy-commerce

${ }^{11}$ John Broder, Bashing EPA is New Theme in G.O.P. Race, N.Y. TIMES, Aug. 17, 2011, at A1.

${ }^{12}$ Ron Paul, 2012 Restore America Now, at http://www.ronpaul2012.com/theissues/ron-paul-plan-to-restore-america/. 
upside down and inside out, and infrequently eliminated entirely. ${ }^{13}$ Interagency working groups, coordinators, and "czars" have come and gone, along with multiple shifts in responsibility for particular firms, industries, and areas of law.

Why all this fuss over organization? Simply stated, what an agency is assigned to do and where it is located matters. As Professor Amy Zegart aptly observed:

organization is never neutral. As any Washington taxi driver can point out, government organization has serious implications for policy outcomes. It matters who has the information, who has the jurisdiction, who has the last word. It matters whether intelligence is collected by diplomats or spies, whether international negotiations are conducted through the Department of State or through back channels in the White House. . . When it comes to selecting, shaping, and implementing. . . policy, the devil often lies in the details of agency design. ${ }^{14}$

In previous work, we analyzed the dynamics that influence the assignment of regulatory duties to an agency, how those dynamics (and the allocation of responsibilities) can change over time, and how the specific combination of regulatory functions and purposes can affect agency behavior. $^{15}$ In this article, we apply the framework we previously developed to the CFPB. Created as a result of the 2011 Dodd-Frank Wall Street Reform and Consumer Protection Act, the CFPB is an independent entity within the Federal Reserve, with responsibility for consumer protection in financial products and services. Combining issues that had previously been handled by seven different federal agencies, the CFPB has regulatory oversight over banks, credit unions, securities firms, mortgage-

${ }^{13}$ Donald F. Kettl, Reforming the Executive Branch of the U.S. Government, 345, 346, Table 1 in Aberbach \& Peterson, supra note 6; RonAlD C. MOE, AdMINISTRATIVE RENEWAL: REORGANIZATION COMMISSIONS IN THE $20^{\mathrm{TH}}$ CENTURY (2003).

${ }^{14}$ Amy B. Zegart, Flawed By Design: The Evolution of The CIA, JCS, And NSC I-II (1999).

${ }^{15}$ David A. Hyman \& William E. Kovacic, Competition Agencies with Complex Policy Portfolios: Divide or Conquer? 2013 Concurrences, available at http://www.concurrences.com/Journal/Issues/No-1-2013/Articles/Competition-agencieswith-complex; William E. Kovacic \& David A. Hyman, Competition Agency Design: What's On the Menu? 8 European Comp. J. 527-538 (2013). See also David A. Hyman \& William E. Kovacic, Institutional Design, Agency Life Cycle, and The Goals of Competition Law, 81 Fordham L. Rev. 2163-2174 (2013). 
servicers, payday lenders, debt collectors, and other financial companies. ${ }^{16}$ The CFPB has a diverse array of tools available to prevent "unfair, deceptive, or abusive" acts or practices in the financial services sector.

The CFPB has been mired in controversy since it was first proposed, including disputes over how it should be structured, where it should be located within the federal bureaucracy, and what powers it should exercise. Because our past work helps cast light on these issues, we analyze the CFPB as a case study of the complexities and contingencies of agency design.

Part II provides a historical perspective on the complexities of designing a public agency. Part III introduces our analytical framework for analyzing the problem of agency design. Part IV specifies seven factors that we believe have proven significant in the success (and failure) of various past combinations of functions. Part V applies our analytical framework to the CFPB. Part VI considers two other issues: the implications of our findings for administrative law, and for the design of other entities. Part VII concludes.

II. Designing a Regulatory Agency: Who, What and Where?

How should the federal government be organized - and who (i.e., which departments, agencies, bureaus, and commissions) should do what? When a law is passed, should responsibility for enforcing it be given to an existing department, agency, bureau, or commission -- and, if so, which one? If responsibility is given to a new department, agency, bureau, or commission, where should it be located in the bureaucratic firmament?

The examples in President Obama's 2011 State of the Union (exports, housing, and salmon) suggest that these organizational issues are straightforward, and that inefficiencies are specific and isolated. Indeed, the graphic that accompanied the on-line version of the State of the Union, reproduced below as Figure 1, suggests that the problem is a bit of a joke, and that is easily remedied once it is recognized as a problem. In fact, as detailed below, the duplication and "jurisdictional chaos" that give rise to the demand for government reorganization are policy perennials.

\footnotetext{
${ }^{16}$ The seven agencies are the Federal Reserve Board; the Office of the Comptroller of the Currency; the Federal Deposit Insurance Corporation; the Office of Thrift Supervision; the National Credit Union Administration; the Federal Trade Commission; and the Department of Housing and Urban Development.
} 
Figure 1: Allocation of Regulatory Responsibility for Salmon

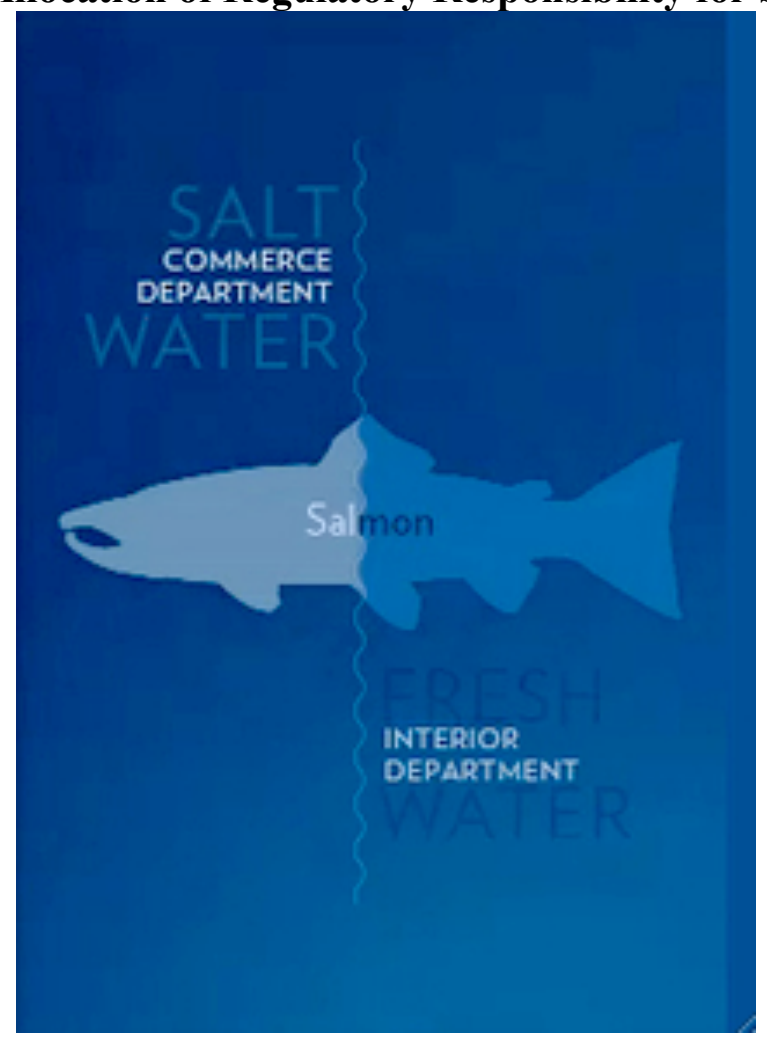

Source: 2011 Enhanced State of the Union Address Graphics, slide 54, available at http://www.slideshare.net/whitehouse/2011enhanced-state-of-the-union-address-graphics

A. How Frequent and Severe is the Problem?

The problem identified by President Obama in his 2011 and 2012 State of the Union Addresses is pervasive and longstanding, and it has proven remarkably resistant (if not completely immune) to repeated reform efforts. Over the past century, numerous public and private blue-ribbon commissions, task forces, advisory councils and working groups have studied how to reorganize the federal government. The conclusions of the National Commission on Public Service in 2003 are typical:

The federal government is a flotilla of many distinct organizational units. Virtually every year new vessels are added to respond to the demands of the time. Occasionally, in response to a broadly perceived national emergency, the vessels are regrouped. . . Virtually never are they combined to eliminate program duplication. Missions are not realigned or even rationalized. Program laps upon program. Responsibilities are not coordinated. . Those who enter 
public service often find themselves at sea in an archipelago of agencies and departments that have grown without logical structure, deterring intelligent policymaking. The organization and operations of the federal government are a mixture of the outdated, the outmoded and the outworn. ${ }^{17}$

The 2003 Volcker report provides some concrete examples of the magnitude of the problem:

Prior to the post 9/11 reorganizations, over 40 federal agencies were involved in activities to combat terrorism. The Department of Housing and Urban Development operates 23 self-sufficiency and economic opportunity programs that target tenants of public housing and other low-income clients. Responsibility for federal drug control strategies and their implementation is fragmented among more than 50 federal agencies. There are over 90 early childhood programs scattered among 11 federal agencies and 20 offices. Nine federal agencies administer 69 programs supporting education and care for children under age five. There are 342 federal economic development related programs administered by 13 of the 14 cabinet departments. Seven agencies administer 40 different programs that have job training as their main purpose. At least 86 teacher-training programs in nine federal agencies fund similar types of services. . . There are 50 homeless assistance programs administered by eight agencies. . . 29 agencies collectively share responsibility for federal clean air, clean and safe water, and better waste management programs. ${ }^{18}$

Analogous paragraphs can readily be found in the reports issued by blue ribbon commissions, task forces, and other entities over the course of the $20^{\text {th }}$ century. ${ }^{19}$ Yet, despite regular reorganizations, the problems persist -

\footnotetext{
${ }^{17}$ National Commission on Public Service, Urgent Business For America: REVITALIZING THE FEDERAL GOVERNMENT FOR THE $21^{\text {sT }}$ CENTURY (Jan. 2003), available at http://www.brookings.edu/gs/cps/volcker/reportfinal.pdf (hereinafter "Volcker Commission"), at 36.

${ }^{18}$ Volcker Commission, supra note 17, at 36-37.

19 Taft, Truman, Eisenhower, Johnson, Nixon, Carter, Reagan, and Clinton used advisory commissions to review the structure and performance of the federal government. The GAO has also issued periodic reports on the problem of duplication. Government Accountability Office, Opportunities to Reduce Potential Duplication in Government Programs, Save Tax Dollars, and Enhance Revenue, GAO-11-318SP (March 2011), available at http://www.gao.gov/products/GAO-11-318SP. A 2012 report from the GAO
} 
and, if anything, have gotten worse over time. ${ }^{20}$

Ironically enough, given the after FDR's 1939 reorganization of the federal government, he had to resolve a dispute over which of two Departments (Interior and Agriculture) should have jurisdiction over the breeding and raising of fur bearing animals. ${ }^{21}$ Roosevelt settled the dispute with a tongue-in-cheek note that referenced the story of the four bears. ${ }^{22}$

President Roosevelt had to deal with such issues on other occasions, including turf battles between the FBI and the Office of Coordinator of Information ("OCI"), and the FBI and the Office of Strategic Services ("OSS"). ${ }^{23}$ For example, when OSS agents burglarized the Spanish embassy in Washington, D.C. in October, 1942, the FBI sent two cars to the embassy, arrested the OSS agents, and sought to bring criminal charges -- jeopardizing the security interests of the United States in order to protect its turf. ${ }^{24}$ Although the OSS was ultimately replaced by the Central Intelligence Agency, the turf war has continued to the present day. ${ }^{25}$

noted that some progress had been made, but most of the organizational chaos remained. Government Accountability Office, Opportunities to Reduce Duplication, Overlap and Fragmentation, Achieve Savings, and Enhance Revenue, GAO-12-342SP (Feb. 2012), at http://www.gao.gov/assets/590/588818.pdf.

${ }^{20}$ On the frequency of reorganization, see JAMES Q. WILSON, BUREAUCRACY: WHAT Government AGEncies Do AND Why They Do It 212 (2000) ("During the 1960s, 270 federal offices were created, 109 were abolished, 61 were transferred, and 109 had their names changed. From 1953 to 1970 the Office of Education was reorganized six times and the Food and Drug Administration eight times.")

${ }^{21}$ In 1939, the Bureau of Biological Survey (Agriculture) and the Bureau of Fisheries (Commerce) were transferred to Interior to form the U.S. Fish and Wildlife Service. The American Fox and Fur Breeders Association proposed to have fur-animal research (previously handled by the Bureau of Biological Survey) transferred back from Interior to Agriculture. Harold Seidman, Politics, Position And Power 88 (Oxford U. Press, 1970).

${ }^{22}$ See Id:

I agree with the Secty of the Interior. Please have it carried out so that fur-bearing animals remain in the Dept. of Interior. You might find out if any Alaska bears are still supervised by a) War Dept., b) Dept. of Agric. c) Dept. of Commerce. They have all had jurisdiction over Alaska bears in the past and many embarrassing situations have been created by the mating of a bear belonging to one Dept. with a bear belonging to another Dept.

P.S. I don't think the Navy is involved, but it may be. Check the Coast Guard. You never can tell.)

We are indebted to Alvin Felzenberger for calling this episode to our attention.

${ }^{23}$ Francis MCDONnell, Insidious Foes: THE AXIS FifTH COLUMn AND the AMERICAN HOME FRONT 170-171 (Oxford, 1995).

${ }^{24} \mathrm{Id}$.

${ }^{25}$ See, e.g., Mark Riebling, Wedge: From Pearl Harbor to 9/11: How the 
More recent examples are easy to find. Why do 15 federal agencies share responsibility for food safety - with the Food and Drug Administration ("FDA") responsible for cheese pizza, and the Department of Agriculture responsible for pepperoni pizza? ${ }^{26}$ Why is the FDA responsible for bottled water, and the Environmental Protection Agency ("EPA") responsible for tap water? ${ }^{27}$ Why is the safety of drinking water on airlines jointly regulated by three federal agencies, with the determination of the responsible agency contingent on where the water is physically located, and the form that it takes (e.g., is it bottled water, tap water, or ice, coffee and tea) $?^{28}$ Why are federal financial literacy efforts "spread among more than 20 different agencies and more than 50 different programs and initiatives"? ${ }^{29}$ Why does regulatory responsibility for eggs bounce between the FDA (Department of Health \& Human Services) and the Department of Agriculture, depending on whether the egg is inside or outside of the chicken, and whether or not the egg is in the shell, or has been cracked open? ${ }^{30}$ How many Institutes should there be in the National Institutes of Health ("NIH"), and should they be organized around specific diseases, organ systems, life stage, field of science, or the profession/technology? ${ }^{31}$ Why is the National Institute for Occupational Safety and Health ("NIOSH") located within the Centers for Disease Control and Prevention ("CDC") instead of NIH or within the Department of Labor? ${ }^{32}$ Why do four federal agencies have authority over outer

SeCret War Between the FBI AND the CIA has Endangered National Security (2002).

${ }^{26}$ Jane Black \& Ed O'Keefe, Overhaul of Food Safety Rules in the Works, WASH. POST, July 8, 2009.

${ }_{27}^{27}$ General Accounting Office, Bottled Water: FDA Safety and Consumer Protections Are Often Less Stringent Than Comparable EPA Protections For Tap Water (June, 2009), available at http://www.gao.gov/new.items/d09610.pdf.

28 EPA, Aircraft Water

http://water.epa.gov/lawsregs/rulesregs/sdwa/airlinewater/regs.cfm. See also http://aircrewhealth.com/Topics/hazards/waterquality.htm.

${ }^{29}$ GAO, Financial Literacy: The Federal Government's Role in Empowering Americans to Make Sound Financial Choices, GAO 11-504T, at http://www.gao.gov/highlights/d11504thigh.pdf

${ }^{30}$ Karen Tumulty \& Ed O'Keefe, The Government tends to resist reorganization, WASHINGTON POST, Jan 28, 2011, at A1.

${ }^{31}$ As it happens, NIH has institutes organized around all of the above possibilities. There are nine disease-focused institutes; four organ system-focused Institutes; two Institutes focused on life stage; three Institutes focused on a particular field of science; and two Institutes that focus on a specific profession or technology. See Michael McGeary \& Philip M. Smith, Organizational Structure of the National Institutes of Health, unpublished background paper on file with authors (2002)

${ }^{32}$ Congress put NIOSH in HHS (then HEW), rather than Labor to distance it from the "highly political workplace enforcement environment." Denny Dobbin, Where to Put 
space $^{33}$ Why did the State Department engage in a decades-long dispute with the Departments of Agriculture and Commerce over which department should be responsible for federal employees stationed outside the United States (usually within foreign embassies) who handled agriculture and trade promotion? ${ }^{34}$

Why is the FDA responsible for both food and drugs, when there is effectively no real overlap between these two industries, other than for some dietary supplements? Why is NOAA in the Department of Commerce and the Coast Guard in the Department of Homeland Security, and the U.S. Public Health Service in the Department of Health \& Human Services, when all three include significant uniformed services, like the Army, Navy, Air Force, and Marines (all of which reside in the Department of Defense)? And, even if NOAA doesn't belong in the Department of Defense, shouldn't there be a better reason for why is it in the Department of Commerce than President Nixon' personal pique at the then-Secretary of the Interior (which was the leading candidate for housing NOAA when it was created)? ${ }^{35}$ Why is the U.S. Forest Service (and responsibility for

NiOSH, Medscape Public Health Perspective, May 31, 2005, at http://www.medscape.com/viewarticle/504483. Stated more concretely, there was a fundamental dispute between those who wanted the Occupational Safety and Health Administration ("OSHA") to aggressively regulate workplace health and safety and those who didn't want there to be an OSHA at all. One part of the resulting compromise was the creation of two separate agencies (NIOSH and OSHA), put in two different departments (HHS and Labor, respectively), with NIOSH responsible for making recommendations to OSHA on workplace health and safety standards, and OSHA responsible for bringing enforcement actions and promulgating regulations. This structure effectively constrained OSHA's ability to set its own regulatory agenda, since it could not do its own research on workplace safety. But see Andy Morriss \& Susan Graham, Defining What to Regulate: Silica \& the Problem of Regulatory Categorization, 58 ADMIN. L. REV. 269, 322-23 (2006) ("This separation of standard setting and enforcement from research 'has its roots in the history of earlier occupational safety and health activities and conflicts between the Department of Labor and the Public Health Service.'”)

When one of us (DAH) presented this paper, he asked the audience to vote where they thought NIOSH belonged (without revealing where it was currently located). Given the choice between the three locations in the text, the overwhelming majority voted to put it in the Department of Labor. Not one person voted to put NIOSH in the CDC.

${ }^{33}$ Tumulty \& O'Keefe, supra note 30.

${ }^{34}$ On the dispute between State and Commerce, see MAURICE STAns, OnE OF THE Presidents' Men: Twenty Years with Eisenhower And Nixon 212-214 (1995). See also http://en.wikipedia.org/wiki/Foreign Agricultural Service

${ }^{35}$ See Steven Eli Schanes, The Battle for the National Oceanic and Atmospheric Administration (NOAA) 1969-71, at http://schanes.wordpress.com/2008/05/21/the-battlefor-the-national-oceanic-and-atmospheric-administration-noaa/. See also Steven Eli Schanes, Putting NOAA Together-1970, at http://schanes.wordpress.com/2008/05/24/putting-noaa-together-1970/; and Eileen L. Shea, A History of NOAA, at http://www.history.noaa.gov/legacy/noaahistory 1.html 
National Forests) in the Department of Agriculture, and the National Park Service (and responsibility for National Parks) in the Department of the Interior, when the territory being supervised is physically contiguous? ${ }^{36}$ Why have the Federal Bureau of Investigations and the Drug Enforcement Administration ("DEA") gotten into turf battles at crime scenes, even though they are both located within the Department of Justice? ${ }^{37}$ Why, when President Obama proposed to move NOAA from Commerce to Interior was the move opposed by both environmentalists and fisheries? ${ }^{38}$

Similar difficulties were created by President Obama's proposal in the 2012 State of the Union Address to move the U.S. Trade Representative ("USTR") from its current location within the Executive Office of the President ("EOP") into the proposed business and trade agency. Trade is a focal point for inter-agency conflict, with each agency emphasizing the issues of most important to its constituents: "Commerce Department officials continually urged U.S. trade negotiators to take a pro-business position, while State Department officials said that non-business foreign policy matters should determine whether the United States wanted to pursue an agreement or a liberalization or tightening up of trade rules." 39 USTR's position in the EOP allows it to serve a trade coordination function, but subsuming it within a larger super-trade bureaucracy placed this role (and USTR's flexibility and autonomy) at risk. ${ }^{40}$ Not surprisingly, USTR's "clients" opposed the relocation/merger. ${ }^{41}$

\footnotetext{
${ }^{36}$ For the largely historical answer, see DANIEL P. CARPENTER, THE FORGING OF Bureaucratic Autonomy: Reputations, Networks, AND Policy InNovations in Executive Agencies, 1862-1928 (2001). See also Howard SEIDMAn, Politics, Positions AND Power: The DynAmics of FEDERAL Organization 126 (5 $5^{\text {th }}$ ed. 1998) ("The Forest Service might well be in the Interior Department today if the historic dispute between Secretary Ballinger and Gifford Pinchot had not left conservationists with a nearly pathological distrust of the department.")

${ }^{37}$ Tumulty \& O'Keefe, supra note 30.

${ }^{38}$ Charles S. Clark, Obama reorganization bid faces challenges on Capitol Hill, Jan. 13, 2012, available at http:/www.govexec.com/oversight/2012/01/obama-reorganizationbid-faces-challenges-on-capitol-hill/35839/; Press Release, Fishermen wary of Obama's reforms, Fishnewseu.com, Jan. 16, 2012, available at http://www.fishnewseu.com/latestnews/world/7378-fishermen-wary-of-obamas-reforms.html.

${ }^{39}$ Reorganization Proposal could impact food safety, USTR, Hagstrom Report, available

http://www.hagstromreport.com/2012news files/2012 0113 reorganization.html

${ }^{40}$ Daniel F. Runde \& Meredith Broadbent, President's Proposed Reorganization of Trade Agencies, Jan. 18, 2012, available at http://csis.org/publication/presidents-proposeddepartment-trade-and-innovation.

${ }^{41}$ Those opposing the relocation/merger included two dairy associations (the U.S. Dairy Export Council and the National Milk Producers Federation) and the American Soybean Association. See USDEC, NMPF raise concerns about U.S. trade policy reorganization impact, http://dairybusiness.com/seo/headline.php?title=usdec-nmpf-raise-
} 
The division of "ownership" over particular areas can result in problems when separate agencies share jurisdiction, and/or must coordinate their efforts. ${ }^{42}$ Profound difficulties can result when agencies do not "get along" or have conflicting assessments of the nature and seriousness of the "problem." ${ }^{43}$ Even when agencies "get along" and agree on the nature and seriousness of the problem, they can have profound disagreements on the optimal solution, and which of the rival agencies is best situated to implement "reform." Conflicts within intelligence agencies, and between intelligence and law enforcement agencies are legendary. ${ }^{44} \mathrm{~A}$ trivial example makes the point: when top brass at the CIA and FBI announced that analysts from each would be detailed to the other, so as to break down these barriers, personnel at both agencies referred to it as a "hostage exchange program. ${ }^{\circ 5}$ As detailed below, inter-service conflicts within the Department of Defense are deeply rooted. Even the children of military personnel are rapidly socialized into the tribal nature of the individual services. ${ }^{46}$

One final complication: all of these examples assume the allocation of regulatory responsibility is static - but history makes it clear that the location of any given agency/bureau/regulatory function is actually quite fluid. The frequency of past reorganizations means that the "home" of any given function is far from permanent, and "it does not take much digging

concerns-about-u-s-trade-pol\&date $=2012-01-17 \&$ table $=$ headlines (

${ }^{42}$ See generally Jason Marisam, Duplicative Delegations, 63 ADMIN. L. REV. 181 (2011).

${ }^{43}$ In re Aiken County, -- F.3d -, No. 10-1050 (D.C. Cir. 2011) ("This case is a mess because the executive agency (the Department of Energy) and the independent agency (the Nuclear Regulatory Commission) have overlapping statutory responsibilities with respect to the Yucca Mountain project.")

${ }^{44}$ See Amy B. Zegert, Spying Blind: The CIA, the FBI, AND the ORIGins of 9/11 (2007); Riebling, supra note 25; Luis Garicano and Richard Posner, What Our Spies Can Learn From Toyota, WALL ST. J. (Jan. 12, 2010) ("The national intelligence apparatus of the U.S. . consists officially of 16 separate agencies, and unofficially of more than 20. Each of these agencies is protected by strong political and bureaucratic constituencies, so that after each intelligence failure everything continues pretty much the same and usually with the same people in charge.")

${ }^{45}$ John Diamond, CIA \& FBI in the Hot Seat, USA TODAY, June, 4, 2002, available at http://www.usatoday.com/news/washington/2002/06/04/hotseat-usat.htm ("As an illustration of the bad feelings between the two agencies, the practice of CIA and FBI analysts working at the other agency is referred to as a "hostage exchange program.")

${ }^{46}$ Mary Ellen Wertsch, Military Brats: Legacies of ChildhoOd Inside the FORTRESS 311, 312 (2006) ("When I was a young child, I understood that we were something called an 'Army family' although I had only a vague idea of what that meant. But I knew one thing for certain: We were most definitely not Navy. . . One Army colonel's daughter told me her father refused to attend her wedding because she was marrying a Navy brat.") 
for an organization archeologist to uncover evidence of prior civilizations and cultures within the Executive branch." ${ }^{47}$ Further, even completely "new" agencies and bureaus are usually cobbled together from "bits and pieces" of other agencies and bureaus. ${ }^{48}$ As Professor Daniel Carpenter observed, "the institutions of the future seem endlessly created from the organization of the past." ${ }^{, 49}$ As we discuss in greater depth below, these complicated genealogies are the result of a polycentric, path-dependent, and intensely political process -- played out repeatedly, over many decades. ${ }^{50}$ But, before we turn to a more systematic consideration of factors that affect the location and combination of functions for a public agency, Part $\mathrm{C}$ explains how the focus on "jurisdictional chaos" misses some of the gains from agency/regulatory duplication and overlap.

\section{Benefits of Agency Redundancy}

Framing the problem as "jurisdictional chaos" is rhetorically effective. After all, who could be in favor of chaos? ${ }^{51}$ But, if one unweights the rhetorical dice, and asks about the costs and benefits of agency/regulatory redundancy, the issue suddenly becomes less clear-cut. In an engineering context, redundancy is usually viewed as an essential attribute in creating a margin of safety. Although the Boeing 777 can fly on only one engine, no one thinks Boeing should just leave the second engine off. ${ }^{52}$ Computer users are supposed to back up their computer files - even though doing so is, by definition, redundant. As these simple examples

\footnotetext{
${ }^{47}$ Seidman, supra note 36 , at 126.

${ }^{48}$ Wilson, supra note 20, at 55 ("Most new agencies are formed out of bits and pieces of old ones.")

${ }^{49}$ Daniel Carpenter, The Evolution of National Bureaucracy in the United States, in ABERBACH \&. PETERSON, supra note 6, at 41, 43 (New agencies are "built from existing agencies and institutions. The institutions of the future seem endlessly created from the organization of the past.")

${ }^{50}$ See Terry M. Moe, The Politics of Bureaucratic Structure: A Perspective on Structural Politics, Self-Interest, and the New Social Regulation, in Can the Government Govern (John E. Chubb \& Paul Peterson, eds.) (Brookings, 1989) (“American public bureaucracy is not designed to be effective. The bureaucracy arises out of politics, and its design reflects the interests, strategies, and compromises of those who exercise political power."); Barry R. Weingast, Caught in the Middle: The President, Congress, and the Political-Bureaucratic System, in Aberbach \& Peterson, supra note 6, at 312, 315 ("Ex ante constraints are designed to mirror the political environment facing the enacting coalition and to stack the deck in favor of particular interests and to disadvantage others.")

${ }^{51}$ But see Heathers (1988) ("Chaos was what killed the dinosaurs, darling.") Similar rhetorical tactics explain other labels, such as "smart growth" and "death taxes."

52 Jacob Gersen, Designing Agencies: Public Choice and Public Law, in ReSEARCH Handbook In Public Law and Public Choice, D. Farber \& A. O'Connell, eds. (2010), at 351 (" $[\mathrm{R}]$ edundancy is a standard design principle in both engineering and organizations.")
} 
illustrate, it is more useful to think about these issues in terms of the optimal level of agency and regulatory redundancy/overlap - a framing which necessarily requires balancing the costs and benefits of such strategies compared to the alternatives. The costs of redundancy/overlap are quite visible, and have attracted considerable attention. So, what are the benefits of redundancy/overlap? More broadly, what explains the agency design choices that we actually observe?

In recent years, a number of legal scholars have focused on these issues - usually in the context of disputes involving a single statute, agency, or substantive area of law. Professor Freeman and co-authors have outlined various ways in which the involvement of multiple agencies can influence agency decision-making for the better, by encouraging or requiring the "deciding agency" to take account of factors and goals it would otherwise downplay or ignore. ${ }^{53}$ Professors Weisbach \& Nussim argue that we should consider tax preferences and spending programs in an integrated fashion, and highlight the organizational logic (focusing on specialization and coordination) of having overlapping programs run by separate agencies. ${ }^{54}$ Professor Bradley suggests that the division of responsibilities between agencies, when coupled with a "rule-based interface," helps coordinate resolution of complex regulatory problems and strengthens presidential control of the administrative state. ${ }^{55}$

Professor Barkow explores the importance of agency design in resisting capture, particularly when dealing with asymmetrical political pressure. ${ }^{56}$ Professor Marisam suggests that "duplicative delegations" make it possible for the President to choose from a "menu of agencies" in deciding which agency is best situated to do what. ${ }^{57}$ Professor Biber highlights the challenges faced by multi-goal agencies, and explores the costs and benefits of various strategies to monitor and motivate such agencies to do better. ${ }^{58}$

${ }^{53}$ Jody Freeman \& James Rossi, Agency Coordination in Shared Regulatory Space, 125 Harvard L. ReV. 1131 (2012); J.R. Deshazo \& Jody Freeman, Public Agencies as Lobbyists, 105 COLUMBIA L. REV. 2217 (2005); Freeman, Freeman urges coordination of agencies in shared regulatory space, Mar. 23, 2011, at http://www.law.harvard.edu/news/2011/03/23 jody-freeman-chair-lecture.html

${ }^{54}$ David A. Weisbach \& Jacob Nussim, The Integration of Tax and Spending Programs, 113 YALE L. J. 955 (2004).

${ }^{55}$ Keith Bradley, The Design of Agency Interactions, 111 COLUMBIA L. REV. 746 (2011).

${ }^{56}$ Rachel Barkow, Insulating Agencies: Avoiding Capture Through Institutional Design, 89 TEXAS L. REV. 15 (2010).

${ }^{57}$ Marisam, supra note 42.

${ }^{58}$ Eric Biber, Too Many Things to Do: How to Deal with the Dysfunctions of MultipleGoal Agencies, 33 Harv. Envtl. L. Rev. 1 (2009). See also Eric Biber, The More The Merrier: Multiple Agencies and the Future of Administrative Law Scholarship, HARVARD 
Professor Gersen emphasizes the benefits of overlapping jurisdiction in solving various agency problems, including bureaucratic drift, and the impact of agency design. ${ }^{59}$ Professor O'Connell highlights the role of rivalry between agencies with overlapping jurisdiction in encouraging higher quality intelligence. ${ }^{60}$ Professors Cohen, Cuéllar, and Weingast describe how the creation of the Department of Homeland Security strengthened Presidential control and simultaneously promoted domestic policy priorities other than homeland security. ${ }^{61}$

Professor Doran explores how the fragmentation of Congressional committee jurisdiction and parliamentary prerogatives help create redundancy, and explores the informational efficiencies and distributive consequences that result. ${ }^{62}$ Professor Macey analyzes the structure and design of administrative agencies in terms of their ability to reduce the agency costs that exist between Congress and the bureaucrats within those agencies, as well as to reduce the chance that "future changes in the political landscape will upset the terms of the original understanding among the relevant political actors." ${ }^{63}$ Finally, Professors McCubbins, Noll and Weingast (McNollGast) explore how Congress can manipulate agency design and decision rules to "stack the deck" in favor of the outcomes favored by those responsible for drafting the legislation in question. ${ }^{64}$

To be sure, we have only described the legal literature on these subjects. Political scientists and public administration scholars have spent decades working on these issues. ${ }^{65}$ Despite this limitation, our abbreviated

L. REV. ONLINE FORUM (2012), at

http://www.harvardlawreview.org/issues/125/march12/forum 868.php;

${ }^{59}$ Jacob E. Gersen, Overlapping and Underlapping Jurisdiction in Administrative Law, 2006 Sup. Cт. ReV. 201. In Designing Agencies, supra note 52, Gersen considers at greater length the public choice perspective on agency design, including the mechanisms of vertical and horizontal control.

${ }^{60}$ Anne Joseph O'Connell, The Architecture of Smart Intelligence: Structuring and Overseeing Agencies in the Post-9/11 World, 94 CAL. L. REV. 1655 (2006).

${ }^{61}$ Dara K. Cohen, Mariano-Florentino Cuéllar, and Barry R. Weingast, Crisis Bureaucracy: Homeland Security and the Political Design of Legal Mandates, 59 StAN. L. REV. (2006) ("By moving a large set of agencies within the department and instilling them with new homeland security responsibilities without additional budgets, the president forced these agencies to move resources out of their legacy mandates.")

${ }^{62}$ Michael Doran, Legislative Organization and Administrative Redundancy, 91 Boston U. L. Rev. 1815 (2011)

${ }^{63}$ Jonathan Macey, Organizational Design and Political Control of Administrative Agencies, 8 J. L. ECON. \& ORG. 93 (1992).

${ }^{64}$ Matthew D. McCubbins et al., Structure and Process, Politics and Policy: Administrative Arrangements and the Political Control of Agencies, 75 VA. L. REV. 431 (1989).

${ }^{65}$ See, e.g., Karen M. Hult, Agency Merger and Bureaucratic Redesign (1987); Beryl A. Radin \& Willis D. Hawley, The Politics of Federal 
summary of the literature makes it clear that there are both costs and benefits to agency/regulatory redundancy. More importantly, dismissing the status quo as "jurisdictional chaos" provides no useful insight into how best to organize or reorganize, once there is agreement that the costs of a particular organizational structure/agency design exceed the benefits. In order to frame an intelligible response to that problem, one must consider how the location and the combination of functions and goals of a public agency affect its performance. We now turn to that issue.

\section{Public Agency Design}

\section{A. First Principles}

Creating a public agency requires one to specify at least five major institutional characteristics: (1) the agency's substantive regulatory responsibilities; (2) the location of the agency somewhere within the federal government; (3) the definition of the range of activity subject to the agency's authority (e.g., economy-wide applicability or limitation to selected sectors or transactions only); (4) the designation of the policy instruments that the agency may use in carrying out its duties (e.g., data collection and reporting, law enforcement, business and consumer education, rulemaking, administrative adjudication, civil and/or criminal authority); and (5) the choice of a governance mechanism (management by a single unitary executive or a multi-member board). Of course, we do not propose to address all of these issues in this article; we are instead trying to give a sense of the scope and complexities that must be dealt with anytime one creates a new public agency.

In a rough sense, the issues are similar to those considered by Professor Ronald Coase in the Nature of the Firm. One can frame these issues in various ways. For example, why do firms decide whether to carry out some functions themselves v. contract with others? When firms are not able to do something themselves, when do they use contracts v. acquisitions

Reorganization: Creating the U.S. Department of EduCAtion (1988); Wilson, supra note 20; Aberbach \& Peterson, supra note 6; DONALD F. KETTL, SYSTEM UndeR Stress: Homeland SECurity ANd AmericAn Politics (2004); Beryl A. RAdin \& Joshua M. Chanin, Federal GOVERnMEnt REORganization: A Policy AND MANAGEMENT PersPeCtive (2009); Zegart, supra note 44; Zegart, supra note 14; DAVID E. Lewis, Presidents And the Politics of AGENCY Design: Political Insulation in THE United States Government Bureaucracy, 1946-1997 (2003). Professor Lewis, in particular, has devoted considerable effort to these issues, focusing on the interface of politics and agency performance. See http://www.vanderbilt.edu/politicalscience/bio/david-lewis.

Economists have also written about these issues, but they have spent considerably more time on the organization of private firms. See Weisbach \& Nussim, supra note 54, at 983-993 for a review of the literature. 
v. joint ventures? Why do firms enter some product lines and geographic areas, and not others? Are conglomerates, which participate in multiple independent and unrelated lines of business, a good idea or not? How important are transaction costs (i.e., the relative costs of out-sourcing versus internal production) and product complementarities (i.e., should a manufacturer of mobile phones also make apps?) in defining the boundaries of the firm?

These questions point to some of the complexities in thinking about the "optimal" boundaries for a government agency's substantive responsibility. ${ }^{66}$ The polar solutions are obviously silly: no one creates an agency and fails to give it something to do, and there are no takers for a "Department of Everything." In between, the dividing lines are less obvious: how does one decide whether a governmental agency should have $\mathrm{N}$ or $(\mathrm{N}+1)$ or $(\mathrm{N}+10)$ areas of responsibility? What counts as a distinct area of responsibility? Does it depend on whether the areas involve separate substantive bodies of law - and how are the boundaries of "separate substantive areas of law to be set?" Should the same agency enforce both civil and criminal laws? Should the agency combine legislative, judicial, and executive functions, or just two of the three - and which two? What arrangement minimizes the possibility of capture by those being regulated? ${ }^{67}$ What arrangement will be most appealing to the Senators and Representatives who create the agency in the first place - as well as those charged with oversight and budgetary authority? If another agency already occupies part of the field, should we expand capacity at the existing agency, add responsibility to the existing agency without expanding capacity, or create an entirely new agency? Should we have multiple agencies responsible for the same general area - and if so, how should their jurisdiction be defined and enforced? If we want closer coordination of policy and implementation, should we combine two (or more) agencies into one, or are other strategies (e.g., creating a coordinating council or a "czar") more effective? What are the differing consequences of creating a new agency, adding new functions to an existing agency, and reorganizing governmental functions? And so on.

To address these questions, we begin with an examination of the forces that have historically shaped the assignment of regulatory tasks to agencies.

\footnotetext{
${ }^{66}$ Some of these parallels are explored in Oliver E. Williamson, Public and Private Bureaucracies: A Transaction Cost Economics Perspective, 17 J. LAW, ECON. \& ORG. 306 (1999). See also Jonathan Klick, Francesco Parisi \& Schulz, The Two Dimensions of Regulatory Competition, 26 INT'L REV. L. ECON. 56 (2006).

${ }^{67} C f$. Barkow, supra note 56 .
} 
B. Constructing The Regulatory Portfolio

Unlike business firms, which set the boundaries of their firms through acquisitions, contracts, expansion and contraction, government agencies generally acquire substantive responsibilities through one of four paths: legislative choice; accident/fortuity; agency expansion into unoccupied policy space; and legislative divestiture.

The simplest case is the assignment of specific functions to a particular agency by legislative action. But even here, there are complications, since regulatory authority may still be shared, concurrent, or exclusive. $^{68}$

Agencies can also acquire regulatory or operational authority by accident or fortuity. An agency with capabilities originally designed to serve one purpose may find those capabilities suitable for other analogous purposes - e.g., "if you've got a hammer, why not help other agencies with nails that need pounding?" Thus, helicopters and warships used to deliver troops into combat also can be used to assist civilians suffering from natural disasters, such as earthquakes or floods.

An agency's regulatory jurisdiction may also be affected by agency action in response to changes in business products or technology. ${ }^{69}$ Consider privacy and data protection policies. Modern advances in communications and information services technology have dramatically expanded the ability of firms to collect and use information about consumer behavior and preferences. The United States does not have an omnibus privacy and data protection statute. Instead, we have statutes that regulate specific sectors (e.g., health care providers' collection and use of data) or specific types of transactions (e.g., financial services), with regulatory authority dispersed among the agencies responsible for administering each of these statutes.

The resulting policy vacuum allowed the FTC to emerge as the leading federal privacy agency, by virtue of several cases it brought against firms that failed to fulfill promises concerning data protection. ${ }^{70}$ The FTC

\footnotetext{
${ }^{68}$ There are numerous instances where regulatory authority is shared between a sectorspecific agency (e.g., the Federal Communications Commission in telecommunications) and a government body with a broader generic mandate to address certain categories of business transactions (e.g., the Department of Justice Antitrust Division and the control of mergers). Alternatively, Congress can grant concurrent authority to two agencies, as is the case with the grant of merger control authority to the DOJ and the FTC.

${ }^{69}$ We exclude technological developments that cause Congress to act. So, the emergence of powered flight resulted in a new branch in the Department of Commerce, which ultimately became the FAA.

${ }^{70}$ See, e.g., Federal Trade Commission, Consumer Electronics Company Agrees to Settle Data Security Charges; Breach Compromised Data of Hundreds of Consumers, Feb. 5, 2009, at http://www.ftc.gov/opa/2009/02/compgeeks.shtm; Federal Trade Commission,
} 
also issued a staff report in December, 2010, proposing a policy framework for handling privacy issues. ${ }^{71}$ The Department of Commerce has sought to play a role into the same policy space, triggering a behind-the-scenes battle for regulatory primacy, which Congress has not yet settled. ${ }^{72}$ In like fashion, the development of broadband networks has sparked a similar dispute between the FTC and the FCC over which agency will oversee this element of the communications sector.

The same dynamic has played out in operational terms within the DOD on several occasions. Technological development invariably triggers intense contests to determine which of the uniformed services will control the deployment of weapons based on the new technology. Consider nuclear weapons. The Air Force and Navy sought to occupy the relevant policy terrain, devising solutions that were based exclusively on each service's area of primary expertise. The Air Force emphasized long-range bombers and intercontinental ballistic missiles. ${ }^{73}$ The Navy built ballistic missile submarines and acquired carrier-based aircraft with the capacity to deliver nuclear weapons. The Army, which was not a major player in the fight, developed intermediate range ballistic missiles and nuclear-capable artillery pieces. Congressional appropriations to each service and allocations to particular weapon systems signaled the winners and losers of the ongoing fight for operational dominance.

Finally, there is legislative divestiture. Perceived failure (particularly catastrophic failure) can result in divestiture of some of an agency's functions, or outright closure/consolidation into another agency. As detailed

Iconix Brand Group Settles Charges Its Apparel Web Sites Violated Children's Online Privacy Protection Act, Oct. 20, 2009, at http://www.ftc.gov/opa/2009/10/iconix.shtm; Federal Trade Commission, CVS Caremark Settles FTC Charges: Failed to Protect Medical and Financial Privacy of Customers and Employees; CVS Pharmacy Also Pays $\$ 2.25$ Million to Settle Allegations of HIPAA Violations, Feb. 18, 2009, at http://www.ftc.gov/opa/2009/02/cvs.shtm; Federal Trade Commission, FTC Says Mortgage Broker Broke Data Security Laws: Dumpster Wrong Place for Consumers' Personal Information, Jan. 21, 2009, at http://www.ftc.gov/opa/2009/01/navone.shtm.

${ }^{71}$ See Federal Trade Commission, FTC Staff Issues Privacy Report, Offers Framework for Consumers, Businesses, and Policymakers, Dec. 1, 2010, at http://www.ftc.gov/opa/2010/12/privacyreport.shtm

${ }^{72}$ See Press Release, Commerce Department Unveils Policy Framework for Protecting Consumer Privacy Online While Supporting Innovation, Dec. 16, 2010, at http://www.commerce.gov/news/press-releases/2010/12/16/commerce-department-unveilspolicy-framework-protecting-consumer-priv.

${ }^{73}$ Interestingly, the Air Force was originally unenthusiastic about ballistic missiles, since they threatened the supremacy of the bomber, which dominated the Air Force culture. But, it was clear that the missiles were going to be acquired, so the Air Force "faced an awkward choice: either preserve the culture at the cost of letting the army and navy have what may turn out to be the weapon of the century, or get on the bandwagon at the cost of modifying the culture." Wilson, supra note 20, at 105. 
below, the Deepwater Horizon oil spill resulted in a fundamental reorganization of the Minerals Management Service ("MMS") in the Department of Interior; the melt-down of the financial markets resulted in the shuttering of the OTS, and transfer of its functions to the OCC; the devastation of New Orleans in the wake of Hurricane Katrina resulted in a reorganization of the Department of Homeland Security ("DHS"); and DHS was created in response to $9 / 11 .^{74}$

The different ways in which agencies acquire (and sometimes lose) portions of their regulatory portfolio has two distinct implications. First, the precise portfolio of responsibilities is never static - meaning that single function/purpose agencies are exceedingly rare. Second, this dynamism is affected by competition with rival agencies, and bureaucratic empire building. Agencies sometimes approach legislators to request ownership of a previously uninhabited policy area or simply seek to expropriate a portion of a rival agency's portfolio. ${ }^{75}$

Given these dynamics, it would be very useful to know which factors contribute to the success or failure of particular combinations, and the associated trade-offs. Part IV turns to this issue.

\section{Who Should Do What: Seven Criteria}

How should we decide who should do what? Based on our earlier work, we highlight seven criteria that reflect our reading of the factors that have historically affected agency design, location, and performance. Each factor should be assessed at the level of the agency/department, rather than any subdivision or bureau within the agency/department, since even facially absurd combinations can look sensible if you drill down far enough into each agency/department's organizational chart. ${ }^{76}$

\footnotetext{
${ }^{74}$ Congressional Research Service, Federal Emergency Management Policy Changes After Hurricane Katrina: A Summary of Statutory Provisions, Nov. 15, 2006, at

http://training.fema.gov/EMIWeb/edu/docs/Federal\%20EM\%20Policy $\% 20$ Changes $\%$ 20After\%20Katrina.pdf

${ }^{75}$ Some agencies share policy areas with other government bodies. In other instances, there is a common boundary, and agencies either contest the location of the property line, or technological change causes a shift.

The process is no different than when a deed defines real estate ownership according to the course of a river. A change in the course of the river creates predictable change (and disputes) over who owns what. In property law, the boundary either moves along with the river (if the change is the recent of accretion) or remains where it was originally (if the change is the result of avulsion). This rule explains why although the Mississippi River generally forms the border between Tennessee and Arkansas (with Arkansas on the east bank, and Tennessee on the West bank), some of the land on the west bank is in Tennessee, and other land on the eastern bank is in Arkansas. See State of Arkansas v. State of Tennessee, 246 U.S. 158 (1918).

${ }^{76}$ See Weisbach \& Nussim, supra note 54, at 958-959 (“Consider, for example, a
} 
We note at the outset that the factors are "squishy," inter-related, and are framed at a high level of generality. We offer them in the spirit of Weisbach \& Nussim: even "relatively crude ideas. . . can help policymakers muddle through the problems they face.",77

\section{Policy Coherence}

How related and consistent are the functions that are to be combined? In economic terms, are the functions complements or substitutes $?^{78}$ Synergies and efficiencies are more likely to result if there are commonalities among the functions, whether derived from a common client population, type of regulated entity, temporal or physical commonalities (including but not limited to common inputs and/or outputs), or even just a shared intellectual framework regarding means and ends.

Of course, policy coherence is not necessarily the highest priority which explains why some Departments (such as Interior and Commerce) are little more than a collection of odds and ends. ${ }^{79}$ Indeed, the Department

proposal to have the IRS run the country's defense system, replacing the Department of Defense. The proposal is not as silly as it sounds. It would not mean that bespectacled revenue agents would be parachuting into the Hindu Kush wearing night goggles, camouflage, and pocket protectors. Instead, an intelligent Commissioner of Internal Revenue would allow his employees to specialize. Revenue agents would specialize in reading financial statements and soldiers would specialize in fighting. Policies under such a proposal might very well continue much as they do today.") With all due respect to Weisbach \& Nussim, we think the proposal is exactly as silly as it sounds. The proposal ignores cultural differences between operators who perform these disparate functions, and the organizational structure that both creates and reflects the distinct cultures of the IRS and DOD.

Consider two examples that help make the point. Crime fighting and domestic intelligence are far more tightly linked than tax collection and national defense, but cultural and organizational factors help explain the FBI's failings in the latter area. See generally Luis Garicano and Richard Posner, Intelligence Failures: An Organizational Economics Perspective, 19 J. ECON. PERSP. 151, 166 (2005) ("If crime fighting requires a geographically decentralized organization with limited sharing of information and strong individual incentives based on outputs, but national-security intelligence requires a geographically centralized organization with extensive sharing of information and careful screening of inputs but low-powered incentives, the organization's geographical, incentive, and information-sharing structure will either be an unhappy compromise or assure poor performance of one of the two missions.") See also RICHARD POSNER, REMAKING DOMESTIC INTELLIGENCE 10, 14-34 (2005). The Air Force is currently facing similar difficulties, in trying to adapt its longstanding officer-pilot based culture to the increasing use of UAVs. Mark Mazzetti, The Drone Zone, N.Y. Times M32 (July 8, 2012).

${ }^{77}$ Weisbach \& Nussim, supra note 54, at 997.

${ }^{78}$ The combination of complementary functions is more likely to result in synergies and efficiencies than the combination of substitutes. Indeed, the combination of substitutes may actually degrade overall performance if it gives rise to internal disagreements over which function should be given primacy.

${ }^{79}$ The Department of Interior, was created in 1849 by combining the General Land Office (from the Department of the Treasury), the Patent Office (from the Department of 
of Interior has been described as "the Department of Everything Else," the "Great Miscellany," ${ }^{80}$ a "slop bucket for executive fragments," and a "hydra-headed monster." 81 John C. Calhoun predicted that "everything upon the face of God's earth will go into the Home Department." 82

This dynamic can also become self-reinforcing. The less coherent the combination of functions in a Department, the easier it becomes to add the next unrelated function or functions. The result is that some departments becoming little more than dumping grounds (or less charitably, garbage cans) for bureaus with non-overlapping portfolios.

Even if the purposes are related, if they are at odds with one another the combination can lead to conflicts of interest, if not outright schizophrenia. ${ }^{83}$ Until it was reorganized in the wake of the Deepwater Horizon oil spill, the Minerals Management Service ("MMS") in the Department of Interior was "charged both with collecting revenue generated by oil and gas drilling to fund the government, and with approving the permits that generate that revenue. . . [leaving the MMS] torn between whether to be a regulator or friend to industry." 84

State), the Indian Affairs Office (from the War Department) and the military pension offices in the War and Navy Departments. Subsequent additions included the census, regulation of territorial governments, exploration of the western United States, management of the jail and water systems in the District of Columbia, management of hospitals, universities, and public parks, and the colonization of freed slaves in Haiti. Department of Interior History, available at http://www.doi.gov/archive/history.html

The Department of Commerce, is responsible for the census, patents and trademarks, weather forecasts, weights and standards, and fishing, among other subjects. Jim Kuhnhnen, Commerce Cuts Coming in Obama's Reorganization, AP, Jan, 29, 2011, at http://abcnews.go.com/US/wireStory?id=12792513

${ }^{80}$ Robert M. Utley \& Barry Mackintosh, The Department of Everything Else: Highlights of Interior History (1989), available at http://www.nps.gov/history/history/online books/utley-mackintosh/interior2.htm

${ }^{81}$ Horace S. Merrill, William Freeman Vilas, Doctrinaire Democrat (Madison, Wisc., 1954), pp. 134,139.

${ }^{82}$ Henry B. Learned, The Establishment of the Secretaryship of the Interior, 16 АM. HistoricAl REV. 751, 768 (1911).

${ }^{83} \mathrm{We}$ focus on inconsistencies in ends or goals, but there can also be inconsistencies in preferred means, even when there is agreement on ends, at least at a high level of generality.

${ }^{84}$ Mark Jaffee \& David Olinger, Tracking down Minerals Management Service's dysfunctional history of drilling oversight, DENVER POST, June 6, 2010, at http://www.denverpost.com/headlines/ci 15236764. In response to these criticisms, and the firestorm of Congressional disapproval that followed the Deepwater Horizon disaster, Secretary of the Interior Salazar reorganized MMS into three separate entities. Press Release, Salazar Divides MMS's Three Conflicting Missions, May 19, 2010, at http://www.doi.gov/news/pressreleases/Salazar-Divides-MMSs-Three-ConflictingMissions.cfm

Similar dynamics help explain the spin-off in 1974 of the National Transportation 
Agencies with dual mandates, such as the Federal Reserve and the FAA are prone to similar difficulties. Since 1977, the Federal Reserve is charged with "promot[ing] effectively the goals of maximum employment, stable prices and moderate long-term interest rates." There is an obvious inconsistency between these goals - and the inconsistency makes the Fed less predictable, and more susceptible to political interference. ${ }^{85}$ The FAA is charged with "fostering air commerce," as well as safety. ${ }^{86}$ When the issue attracted public attention, Congress responded by modifying the dual mandate, but the change had limited impact on the culture of the FAA. ${ }^{87}$

One should not overstate the necessity for consistency within a single department or agency. Sound policy-making usually requires the balancing of competing interests. Consider banking regulation, where solvency must be balanced against consumer protection. If solvency and consumer protection are handled by distinct agencies, each will focus on the areas within their respective domains, and discount or ignore entirely the other's area of responsibility. Yet, that approach is a recipe for regular battles between the agencies as to which should prevail on an issue that implicates both sets of interests. A decision balancing the relevant considerations will eventually have to be made by someone - either within a single agency, if both functions are combined, or at a higher level if the two (or more) involved agencies are unable to agree amongst themselves. Obviously, the mission and location of the CFPB, and the reorganization of MMS raise these issues in a very concrete way. ${ }^{88}$

The problem gets stickier when the interests that must be balanced involve agencies with different goals and priorities. ${ }^{89}$ Which agency is the

Safety Board from the Department of Transportation, and the separation of the Atomic Energy Commission into the Energy Research and Development Administration and the Nuclear Regulatory Commission. Such splits can create difficulties when the separated agency is more susceptible to capture than was the case when it was part of a larger entity with a more diversified portfolio. See Mark Seidenfeld, Bending the Rules: Flexible Regulation and Constraints on Agency Discretion, 51 Admin. L. Rev. 429, 465 (1999); Barkow, supra note 56.

${ }^{85}$ Compare George F. Will, The Trap of the Federal Reserve's Dual Mandate, WASH. Post, Nov. 18, 2010 with Ben Bernanke, Federal Reserve Communications, Nov. 14, 2007, at http://www.federalreserve.gov/newsevents/speech/bernanke20071114a.htm

${ }^{86}$ MARY SChIAVo Flying Blind, Flying SAFE 51, 65 (1997). ("If outsiders viewed the FAA as encumbered by a divided loyalty and hamstrung by its dual mandate, the FAA didn't seem to share that confusion. The tombstone mindset made plain its loyalty to the cost-conscious interests of the aviation industry.")

${ }^{87}$ Id. at 203, 206.

${ }^{88}$ Interestingly, the press release announcing the reorganization of MMS highlights the benefits of avoiding agencies with conflicting missions - but it says nothing about the necessity of integrating the conflicting decisions that will result from separate agencies.

${ }^{89}$ See Seidman, supra note 36, at 144 ("If agencies are to work together harmoniously, they must share at least some community of interests about basic goals. . Senator Frank 
"decider" will significantly affect the outcome of any given dispute, as well as whether particular circumstances count as "disputes." Each agency will predictably focus on the issues within their regulatory bailiwick, and be more attentive to the industries and groups they deal with most frequently. For example, we would expect DOD to focus on military preparedness and discount environmental concerns, while EPA would likely have the opposite tendencies. This dynamic results in predictable disputes between agencies with conflicting goals and priorities - including the dispute over the clean up of hazardous waste on military bases $;{ }^{90}$ the magnitude of the risk posed to endangered species and the general population by military training and technology; ${ }^{91}$ the environmental risks created by the Keystone XL pipeline; ${ }^{92}$ and the balancing of industrial development (and the associated employment) against population health and environmental justice claims.

\section{Branding/Credibility}

A public agency's "brand" conveys a message about the agency's priorities and aims to both internal and external constituencies. The brand can become diluted and/or confused if the agency has too many responsibilities, or if the responsibilities are not complementary and consistent. A diluted/confused brand can create confusion for agency personnel about which projects ought to be selected; what theory ought to motivate the pursuit of individual matters; what decision rules should be applied to resolve disputes; and the relative priority and seriousness of

Moss ascribed the conflict between the National Park Service and the Army Corps of Engineers over the Florida Everglades to 'uncoordinated activities. Park service officials complained that the engineers drained the Everglades National Park almost $d r y$ in their efforts to halt wetlands flooding and reclaim glad country for agriculture. The Army Corps of Engineers argued that wetlands were 'for the birds' and flood control for the people.")

${ }^{90}$ Lyndsey Layton, Pentagon Fights EPA on Pollution Cleanup, WASH. Post, June 30, 2008 available dyn/content/article/2008/06/29/AR2008062901977.html.

${ }^{91}$ See, e.g., Edward Walsh, Despite protest, Navy resumes bombing exercises on Vieques/Training interrupted briefly -- 14 arrests, Wash. Post, Apr. 28, 2001 ("The Navy resumed practice bombing on the small Puerto Rican island of Vieques yesterday, intensifying a debate that has pitted what the Navy says is the vital need for realistic training exercises against the health concerns of the island's population and the Puerto Rican government.")

92 Elana Schor, Canada-U.S. Oil Pipeline Poses Few Environmental Risks -- State Dept., N.Y. Times, Aug. 26, 2011 (noting that pipeline supporters view EPA as a "de facto ally of environmentalists. Robert Jones, vice president of the Keystone pipeline system at TransCanada, said earlier this month that "I want to be responsive" to EPA's concerns, but 'the frustration I have is that I might as well be talking to NRDC or the Sierra Club."') 
particular projects/matters. ${ }^{93}$ Agencies with diluted/confused brands are more likely to be perceived as operating inconsistently.

These branding dynamics also influence agency credibility. The better the reputation an agency has with Congress and congressional staffers, the more likely it is to receive adequate funding, and not be subjected to routine second-guessing/reversal. Similar dynamics apply in court; agencies get the deference that courts think they deserve - and reputation drives desert. Finally, the better the reputation an agency has with the parties it regulates, the more likely it is to be able to extract a favorable settlement without full-blown adversarial proceedings. ${ }^{94}$

The bundling of functions also influences an agency's reservoir of political capital. In our experience, regulatory bodies are continually engaged in a process of accumulating and spending political capital. Combining a function that generates political capital surplus with a function that runs political capital deficits may give an agency greater ability to perform deficit-prone functions that are important to the larger economy. Conversely, an agency whose portfolio of responsibilities ensures that it always runs a political deficit is an agency that has no constituency. ${ }^{95}$

${ }^{93}$ See Janice Revell, Interview with John Taylor, Money Magazine 93, 96 (Aug. 2012) ("The Fed needs to focus on a single goal of long-run price stability. We should remove the Fed's dual mandate of maximum employment and stable prices, which was put into effect in the 1970s. From 2003 to 2005, the Fed held interests rates too low for too long. A primary reason was its concern that raising rates would increase unemployment. . . More recently, the Fed has cited concerns over employment to justify its interventions, including quantitatitive easing. Removing the dual mandate would take away that excuse.") (emphasis supplied).

See also Wilson, supra note 20, at 55-59 (describing how the Economic Cooperation Administration and the Central Intelligence Agency were profoundly affected by the personnel they acquired from other agencies, given the open-ended nature of the original mandate (i.e. the brand) for each agency). Indeed, as Wilson concisely observes, "if a new agency has ambiguous goals, the employees' prior experience will influence how its tasks get defined.") Id. at 55. See also Seidman, supra note 36 at 125-26 ("Government officials have an instinctive drive to reproduce the organizations, systems, and procedures with which they are most familiar. When asked to develop a self-financing plan for the rural electrification program, the Agriculture Department inevitably proposed an exact duplicate of the farm credit banks.")

${ }^{94}$ At her first oversight hearing involving the nations' financial regulators, Senator Elizabeth Warren asked each regulator the last time they had taken a major firm to court. None of the regulators knew the answer to the question. Although Warren's question was hailed as welcome example of tough questioning, it actually betrayed a complete misunderstanding of how regulatory agencies actually work. More likely, Senator Warren knew that the question was misleading and deeply stupid, but asked it anyway, assuming the public would be taken in by her empty posturing.

${ }^{95}$ See Susan E. Dudley, Lessons Learned, Challenges Ahead: Is There a Constituency for OIRA, REGULATION 7-8 (Summer, 2009) ("OIRA's mandate is to advance the general public interest. . . Hence there is no concentrated constituency for OIRA.”) 
Such considerations help explain why agencies sometimes resist the addition of new responsibilities, even when acceptance would result in a greater budget and more visibility. ${ }^{96}$ A similar dynamic explains why agencies sometimes try to get rid of responsibilities that senior agency personnel believe detract from the agency's core mission. ${ }^{97}$

3. Capacity/Capability

Agency resources are scarce, just like everything else. Assigning N +1 functions to an agency that only has the resources (whether measured by headcount, band-width, or credibility) to handle $\mathrm{N}$ responsibilities is asking for trouble. Stated differently, an agency with multiple discrete functions can easily find itself with too many things to do, relative to the pool of talent that it has available. One needs a critical mass of talent to do any one thing well; to do multiple things well requires both sufficient capacity and continuous fine-tuning of the agency's allocation of resources. ${ }^{98}$ Absent such conditions, agencies will necessarily engage in policy triage. Agency employees will respond accordingly, sorting themselves to work in particular areas - with their choices dictated by their ambition and enthusiasm. ${ }^{99}$ The result is that some areas will flourish and others will languish - even if budgets keep pace with new responsibilities (which they almost never do). ${ }^{100}$ Triage is necessary if the agency is to keep its head

\footnotetext{
${ }^{96}$ Wilson, supra note 20, at 180 ("For years members of Congress tried to persuade J. Edgar Hoover that the FBI should take over federal responsibility for investigating drug trafficking.")

${ }^{97}$ See Wilson, supra note 20, at 108-109 (noting that in 1973 and again in 1974, the Department of Agriculture tried to get rid of responsibility for the Food Stamp program, since it viewed itself as being in the "food business" - not the "welfare business.")

${ }^{98}$ Wilson, supra note 20 , at 378 ("[W]e live in a country that despite its baffling array of rules and regulations and the insatiable desire of some people to use government to rationalize society still makes it possible to get drinkable water instantly, put through a telephone call in seconds, deliver a letter in a day, and obtain a passport in a week. . . One can stand on the deck of an aircraft carrier during night flight operations and watch two thousand nineteen-year-old boys faultlessly operate one of the most complex organizational systems ever created. There are not many places where all this happens. It is astonishing that it can be made to happen at all.")

${ }^{99}$ Mark Mazzetti, The Way of the Knife: The CIA, A SeCret Army, AND a War AT THE ENDS OF THE EARTH 14 (2013) ("Hundreds of CIA analysts were now working on terrorism, which was understandable in the aftermath of an attack that killed nearly three thousand Americans. But it became immediately obvious to the analysts that the path to career advancement at the CIA was to start working on terrorism, with the goal of producing something that might be read to the president early one morning inside the Oval Office.") (emphasis supplied)

${ }^{100}$ See, e.g., Ladd Wiley \& Steven A. Grossman, Does FDA Have Enough Funding to Fulfill its Critical Role in Protecting the Public Health? 1 FDLI FoOd AND DRUG POLICY FORUM (2011).

To be sure, there is always competition for resources, regardless of the number of functions an agency is performing. But, combining functions within a single department
} 
above water, but doing so means that "law in action" is quite different than "law on the books." It is also a recipe for recriminations and oversight hearings when an issue that didn't make the cut for regulatory attention blows up. ${ }^{101}$

Capacity is not the same thing as capability. Capability determines whether an agency has the tools to make good decisions, and does so. An agency with enforcement responsibilities first needs the statutory authority to exercise its will, and an adequate set of remedies with which to enforce compliance. Once it is so armed, it will predictably make two types of errors: Type I (intervening when it should not, or a false-positive), and Type II (not intervening when it should, or a false negative). The institutional design question is whether an agency with multiple (and potentially competing) functions and purposes is likely to make more or fewer mistakes - and perhaps, of which type. ${ }^{102}$

A related point. Expansion of the agency's substantive mandate can degrade capability, even if all else remains equal. As the agency's authority grows, its leadership and staff may acquire an exaggerated sense of the institution's ability to perform effectively, and pay less attention to whether the agency's commitments match its capabilities. These circumstances can result in agency leadership "over-promising and under-delivering." A related problem is that the more expansive an agency's mandate, the more likely it is that Congress will turn to the agency to address developments that do not fit neatly elsewhere - even if those problems do not actually play to an agency's strengths. Thus, an agency with expansive powers becomes a default option for handling the latest problem, regardless of whether the agency's actual capacity and capabilities supply effective means for achieving a good solution. ${ }^{103}$

Capability is also influenced by the degree to which agency personnel self-critically assess both means and ends. When a single agency has sole responsibility, the risks of groupthink and tunnel vision increase. When multiple agencies share responsibility for a particular area, there is a

merely shifts the problem to a less transparent setting for resolution. The funding/resource allocation problem is necessarily less visible if it is resolved within a single agency. Barring a whistle-blower, external constituencies will never learn the details of who wanted what - and what is no longer being done with the same enthusiasm, if at all.

${ }^{101}$ See, e.g., AP, Risks of tainted food rise as inspections drop, Feb. 26, 2007, at http://www.msnbc.msn.com/id/17349427/ns/health-infectious diseases/t/risks-taintedfood-rise-inspections-drop/

${ }^{102}$ In principle, both types of error are equally problematic; it is the overall frequency of error that matters. In practice, false positives are viewed as more problematic than false negatives, since they are more visible, and the aggrieved constituency can readily mobilize in opposition.

${ }^{103}$ As we have detailed elsewhere, the FTC has periodically run afoul of this dynamic. 
feedback loop for surfacing and resolving disagreements regarding such matters, at the cost of having the dispute spill into public view. The controversy over the desirability of drone strikes in Pakistan exemplifies this dynamic. ${ }^{104}$

4. Resilience: Is the Existing Assignment of Functions Adaptable and Sustainable?

Statutes routinely allocate jurisdiction according to the technology used to supply a product or the status of the organization that provides the service. What happens when the character of the industry is altered by technological change or the emergence of new categories of suppliers of the sector's goods or services? Regulatory jurisdictional boundaries can shift over time in much the way that the movement of a river will sometimes alter rights in real property. ${ }^{105}$ When such changes take place, multiple agencies may seek to exercise authority by arguing that the reconfigured industry falls within their purview. A sustainable assignment of functions will be able to adapt to such changes; a non-sustainable assignment will not, making bureaucratic warfare between the rival agencies a very real possibility. ${ }^{106}$

Examples of this phenomenon are easy to find. The SEC and CFTC waged a decade-long dispute over products that arose at the interface of their respective regulatory authority. ${ }^{107}$ Financial services regulation routinely raises this problem, because regulatory authority is usually tied to the type of entity being regulated, and not the type of product being offered. $^{108}$ (The CFPB represents an obvious counter-example, which we address below). Border disputes can easily trigger a vicious bureaucratic turf war, diverting attention from substantive concerns - particularly when the terms on which the dispute is resolved can trigger dramatic shifts in the allocation of regulated firms across agencies. An adaptive regulatory framework would clearly allocate regulatory authority over a particular area

\footnotetext{
${ }^{104}$ See Mark Bowden, The Killing Machines, Atlantic, Sep. 2013, at 58, 65-66 (describing ongoing conflicts between Department of State, and the CIA and Department of Defense over the merits of specific drone strikes, and the larger policy, as well as whether the CIA or State would decide such matters.). See also Mazzetti, supra note 99, at 291-93.

${ }^{105}$ See supra note 75.

${ }^{106}$ Cf. DAvid C. King, Turf Wars: How Congressional COMmitTeEs Claim JURISDICTION 2 (1997) ("As with nations and hunting groups, poorly defined boundaries lead to wasteful skirmishes.")

${ }^{107}$ Board of Trade v. SEC, 677 F.2d 1137 ( $7^{\text {th }}$ Cir. 1982), vacated as moot, 459 U.S. 1026 (1982); SEC v. American Commodity Exchange, 546 F.2d 1361 (10 ${ }^{\text {th }}$ Cir. 1976); SEC v. Univest, Inc., 410 F. Supp 1029 (D. Ill. 1976).

${ }^{108}$ ANNE M. KHADEMiAn, CHECKING ON BANKS: AutONOMY AND ACCOUNTABILITY IN THREE FEDERAL AGENCIES 126-127 (1996).
} 
to a specific regulatory agency -- instead of forcing personnel at multiple agencies to spend considerable time and effort disputing the allocation of responsibility.

Resilience is obviously not as important as some of the other factors, because problems will only emerge over time, if at all. But, the absence of properly defined jurisdictional boundaries will eventually lead to border wars between agencies/departments, and turf wars among congressional committees. Creating an adaptable and sustainable grant of regulatory authority helps reduce the amount of time spent on such activities.

\section{Cohesion}

When discrete functions are combined in a single agency or department, the result is usually the creation of separate operating units for each function. As individual operating units become more specialized and autonomous, they quickly develop norms, goals, and priorities that predictably differ from other units in the same agency or department. Over time, this process results in units being staffed by personnel whose interests, training, and abilities focus narrowly on the work of their unit and have little understanding of the backgrounds and activities of other units underneath the same institutional roof. Predictably enough, individual units start to see one another as rivals for prestige, headcount, and budgetary resources.

This rivalry is usually either beneficial or destructive. ${ }^{109}$ A final possibility is there will be neither beneficial nor destructive rivalry; individual units will simply not acknowledge the existence of the other units. Issues of culture and history loom large in determining which of these three outcomes will result.

To be sure, such difficulties are likely to arise whether we are dealing with a single agency or multiple agencies that are expected to coordinate their efforts. And, such difficulties can exist within a single department. ${ }^{110}$ But, matters are often much worse across divisions within a single agency or department, such as the legendary conflicts between the rival military services contained within a single Department of Defense:

It was the late 1950s and General Curtis LeMay was the Chief of Staff of the Air Force. The Air Force and the Navy at that time were vying for who would have the primary mission of the strategic defense of the country. The Air

${ }^{109}$ Rivalry will be beneficial if it results in synergies that serve the larger aims of the agency. Rivalry will be destructive if it manifests itself in credit-claiming or other measures that enhance the visibility of the operating unit as an end in itself.

${ }^{110}$ More colloquially, these are referred to as the brown shoe, black shoe, and felt shoe Navy. Wilson, supra note 20, at 106. 
Force was advocating its land based strategic bombers and intercontinental ballistic missiles. The Navy was advocating its ballistic missile submarines and putting nuclear capable aircraft aboard aircraft carriers. The debate was heated and there was not enough money to do both. The future missions of both services were at stake. An Air Force Colonel was briefing General LeMay on the Soviet threat versus the strategic requirements funded in the budget. The Colonel told General LeMay that the Russians, our enemy, were capable of . . . and at that point General LeMay stopped him. LeMay was quoted as saying, "The Russians are our adversary. The Navy is our enemy." 111

Other examples of inter-service attitudes (and their consequences) are not hard to find. The Air Force is responsible for close air support of ground operations, but, air force culture is "based on flying highperformance fighters and long-range bombers, especially the latter." 112 Not surprisingly, the Air Force historically gave "minimal attention to close air support and buys just enough attack aircraft to protect its claim to the close air support mission. Meanwhile, the Army, unsure that it can rely on Air Force support when it is needed, purchases a vast fleet of attack helicopters which, while more expensive than attack planes and potentially far more vulnerable, can be placed under direct Army command."113

To summarize, the coordination of functions and responsibilities will not happen merely because previously separate bureaus are combined into a single department. ${ }^{114}$ Indeed, the more each bureau attempts to build esprit de corps and signal that it is truly elite, the less likely "joint-ness" will result. Such dynamics have long complicated attempts to deploy "special ops" teams from different branches of the military in an integrated fashion particularly when one adds in that special ops has collectively been long regarded with collective suspicion by the "regular" military. When one adds the CIA into the mix, it is easy to understand why joint-ness has been such a challenge. $^{115}$

111 John Melchner, Managing the Budget Process, J. PUB. InTEGRITY 11, 13 (Fall/Winter, 1998), available at http://www.ignet.gov/randp/jpifw98.pdf.

${ }^{112}$ Wilson, supra note 20, at 186.

113 Richard A. StubBing, THE DEFEnSE GAME 142 (1986)

114 See, e.g., DENNIS D. RILEY \& BRYAN E. BROPHY-BAERMANN, BUREAUCRACY AND THE POLICY-MAKING PROCESS 71 (2006) ("A specialist in marine biology may in some sense work for the Department of Commerce, but in his or her mind, the job is not with the Commerce Department or even with the NOAA, but with the National Marine Fisheries Service.")

${ }^{115}$ Marc Ambinder, The Secret Team that Killed Bin Laden, NATiOnAL J. May 3, 
In like fashion, the CIA has had a long-standing cultural conflict between analysts and field agents, as well as ongoing debates between internal communities that favor either reliance on high technology monitoring systems (e.g., reconnaissance satellites) or "Humint" (on the ground in-person collection of intelligence). ${ }^{116}$ Those who design and manage intelligence gathering through advanced technology systems tend to have backgrounds in science and engineering. The human intelligence community tends to be drawn from individuals with skills in the social sciences. Not surprisingly, each individual unit believes it has a monopoly (or near-monopoly) on the optimal approach to intelligence gathering and analysis, and the efforts of other units are viewed with disdain. The problem is not limited to the uniformed services: the U.S. Forest Service has experienced similar difficulties as it has expanded from an agency staffed solely by foresters to a more diversified ecosystem. ${ }^{117}$

As these examples illustrate, the combination of related functions within a single department or agency does not mean that good things will inevitably result. Indeed, destructive rivalry can mean that $2+2=1$, instead of 4 .

6. Collateral Effects on the Regulatory Ecosystem

The government is already thickly planted with bureaus, agencies and inter-agency working groups, departments and commissions, and many of these institutions have overlapping authority. The fact of overlapping authority typically elicits effort by the agencies with shared jurisdiction to

2011, at http://www.nationaljournal.com/whitehouse/the-secret-team-that-killed-bin-laden20110502; Greg Miller \& Julie Tate, CIA Shifts Focus to Killing Targets, WASH. Post, Sep 1, 2011 at A1 ("Osama bin Laden was killed by U.S. Navy SEALs, but the operation was carried out under CIA authority, planned in a room at agency headquarters and based on intelligence gathered over a period of years by the CTC. The assault was the most highprofile example of an expanding collaboration between the CIA and the U.S. Joint Special Operations Command, which oversees the nation's elite military teams. Their comingling at remote bases is so complete that U.S. officials ranging from congressional staffers to high-ranking CIA officers said they often find it difficult to distinguish agency from military personnel.")

${ }^{116}$ See Mazzetti, supra note 99, at 55-56 ("The CIA is actually a fragmented cliquish culture, more like a public high school than many inside the agency care to admit. Jockish paramilitary officers tend to shun the nerdy analysts, who regard the paramilitary operatives as knucle-draggers. At the top of the pyramid are the case officers - the spies who go out in to the world - who believe they are doing the real work of the CIA and like to boast that they don't follow orders from desk jockeys at headquarters.")

${ }^{117}$ Wilson, supra note 20, at 65 ("foresters dislike the tendency of engineers to elevate mechanical soundness over natural beauty, of biologists to worry more about endangered species than about big game, and of economists to put a price on things foresters regard as priceless.") 
coordinate their efforts. ${ }^{118}$ These efforts do not arise because the agencies in question like each other. ${ }^{119}$ But, agencies generally come to realize the need, at least on some level, to avoid destructive duplication and to invest in joint activities. In ways that are usually invisible to external observers, agencies will spontaneously create a vibrant and interlocking ecosystem of cooperation. ${ }^{120}$

When circumstances change (i.e., when regulatory tasks are reallocated, or a new agency is inserted into the mix, or new powers are given to an existing agency), the regulatory ecosystem is likely to be disrupted. The new entrant may siphon off money and personnel, making it difficult for incumbent agencies to perform their existing responsibilities. Reallocation of authority may also upset long-standing understandings that formed the basis for fruitful inter-agency collaboration. The entrant may receive a substantive mandate whose formal commands resemble the language that appears in the statutes of other regulatory authorities. The interpretation of the new entrant's mandate in one judicial could spill over into the interpretation of the mandates of other agencies in separate cases.

To be sure, Congress certainly has the authority to close down an agency entirely, or substantially limit its jurisdiction and authority - and it knows how to do that when it wants to. But, the kinds of regulatory reorganizations we have been describing usually do not reflect that objective - meaning that the damage to the regulatory ecosystem is often an unintended consequence of Congressional failure to understand that personnel would migrate to the new and more glamorous and higher paying outpost - leaving other parts of the regulatory ecosystem permanently blighted. To summarize, the wisdom and net functional benefits of any specific realignment of regulatory authority will depend heavily upon

\footnotetext{
${ }^{118}$ Sometimes the deliberate duplication of responsibility stems from Congressional desire to test alternative institutional means of delivering a desired policy result. See William E. Kovacic, Downsizing Antitrust: Is It Time to End Dual Federal Enforcement? 41ANTITRUST BULLETIN 505 (1996). On other occasions it reflects an explicit desire to use interagency rivalry to spur performance improvements. See William E. Kovacic, Procurement Reform and the Choice of Forum in Bid Protest Disputes, 9 ADMIN. LAW J. AM. UNIV. 461 (1995). Finally, technological change and market developments can give rise to regulatory overlaps "by accident."

${ }^{119}$ Rivalry among agencies to be seen as the lead institution in a given field of regulation is inevitable, as perceptions of primacy influence congressional budgetary allocations, affect staff recruitment, and generally shape an agency's self-image. In analyzing the conduct of public institutions, one rarely goes wrong by overestimating the power of parochialism and self-interest to warp behavior.

${ }^{120}$ The means of cooperation and coordination range from formal exchange of written memoranda of understanding to the creation of interagency working groups to less formal (but still important) personal interaction among agency heads, senior managers, and case handlers.
} 
whether the changes build upon a sophisticated understanding of the existing regulatory ecology.

\section{Political Implications}

Politics is a major factor in the design and location of government agencies and functions, because decisions about where to place certain responsibilities are simultaneously decisions about who will resolve certain disputes, and, in turn, what the outcome is likely to be. ${ }^{121}$ When the House of Representatives was considering a climate change bill in 2009, the chair of the House Agriculture Committee made it clear he would kill the bill if it allocated responsibility for determining whether farmers would receive credit for "tilling and conservation practices that keep carbon dioxide stored in the soil" to the EPA, but would allow it to go forward if responsibility for the same task resided in the Department of Agriculture. ${ }^{122}$ The choice of regulatory responsibility for what might at first glance appear to be a ministerial task had real significance; "environmentalists and the bill's main sponsors feared that the Agriculture Department might use lax standards, which would blow a hole through the nationwide cap on carbon dioxide emissions." ${ }^{123}$ When President Franklin Roosevelt's reorganization committee proposed that all federal loan programs should be consolidated under the Treasury Department, FDR vetoed the suggestion, observing "that won't work. If they put them in the Treasury, not one of them will ever make a loan to anybody for any purpose. There are too many glass-eyed bankers in the Treasury." 124 More recently, privacy advocates have expressed skepticism about the Obama Administration's Internet privacy

${ }^{121}$ See also Seidman, supra note 36 at 137 (detailing how user organizations lobbied to have the Army Corps of Engineers placed in charge of the St. Lawrence Seaway, since they expected it would adhere to its long-standing policy that inland waterways were "public highways open to use of the public generally without restriction," and would accordingly not impose user charges.)

${ }^{122}$ Derek Thompson, The Collin Peterson Climate Change Compromise, THE ATLANTIC, available

http://business.theatlantic.com/2009/06/the collin peterson climate change compromise 1.php

${ }^{123}$ Steven Mufson, Vote Set on House Climate Bill, Wash. Post, June 24, 2009, available at http://www.washingtonpost.com/wpdyn/content/article/2009/06/23/AR2009062303456.html

${ }^{124}$ A.J. WAnN, The President at Chief Administrator - A Study of Franklin D. Roosevelt, Public AfFairs Press, 1968 at 103-104, cited in Seidman, supra note 22, at 118-119. For a similar observation about the Federal Housing Authority, see Riley \& Brophy-Baermann, supra note 114, at 71 (noting that FHA was initially staffed by "real estate people and mortgage brokers," and the "values and prejudices" of those individuals resulted in a definition of agency success tied to "the number of loans made and the repayment record" - leading it to spend most of its resources on loan guarantees for newly constructed single family owner occupied homes - which resulted in the suburbs. 
proposals because the Department of Commerce is taking the lead, instead of a more pro-consumer agency, like the FTC. ${ }^{125}$

Once regulatory authority has been allocated in the first instance, Congressional committees defend their turf with vigor and panache. In part, this is defensible, since there are gains from expertise. Individual members gain knowledge and experience with an agency's operations over a period of years. Proposals to transfer regulatory authority to an agency that is overseen by a different committee places that investment of intellectual capital at risk. Legislators may also be reluctant to allow others to take ownership of "their baby," fearing their successors may not share their priorities. Finally, individual members of Congress derive important electoral advantages from the committees on which they service, including access to campaign contributions from those who are affected by the activities of government agencies subject to the oversight of the committees. Oversight of a specific government agency creates a revenue stream that flows from the affected industry to the committee's members. Reorganization measures that alter an agency's powers can reduce or eliminate the revenue stream to a given committee. This dynamic makes it clear why Congress takes a keen interest in reorganization. ${ }^{126}$

Agency personnel are acutely conscious of these considerations, and will dismiss out of hand organizational changes that create political difficulties. ${ }^{127}$ When agency personnel are not sufficiently sensitive to these dynamics, members of Congress are quick to remind them of the error of their ways. We observed this dynamic first-hand in 2002, when the FTC and DOJ jointly proposed to change the way in which they handled cases in which both had jurisdiction under the Clayton Act. Among other features, the agreement would have given DOJ exclusive jurisdiction over mergers in the the telecommunications and media sectors, while reserving electric power, health care, and aerospace to the FTC. Although the proposal attracted bipartisan support and was hailed by antitrust practitioners, business groups, and former FTC and DOJ personnel, it was ultimately sunk by the vehement opposition of Senator Ernest Hollings, who argued that mergers among media corporations should be reviewed by the FTC. As chairman of the Commerce Committee, Hollings had oversight authority over the FTC, but not over the DOJ (which fell within the jurisdiction of the

${ }^{125}$ See Edward Wyatt, White House, Consumers in Mind, Offers Online Privacy Guidance, N.Y. TIMES, Feb. 23, 2012, at B1 ("A concern is that the administration's privacy effort is being run out of the Commerce Department.")

${ }^{126}$ See generally King, supra note 106, at 2 ("For individual legislators, the payoffs for winning in turf wars include expanded power, greater prestige, opportunities to make a personal mark on important legislation, and improved services to voters.")

127 Steven Eli Schanes, Creating NOAA - The Coast Guard, at http://schanes.wordpress.com/2008/05/24/creating-noaa-the-coast-guard/ 
Senate Judiciary Committee). Hollings threatened the budgets of both agencies unless the clearance agreement was abrogated. Why was Hollings so vehement about this issue? Presumably, he feared that the plan would have largely eliminated the flow of campaign contributions he received from telecommunication and media corporations, and he apparently concluded that any new campaign contributions from electric power, health care, and aerospace firms would not be enough to make up the deficit. ${ }^{128}$

Similar considerations help explain why the reorganization that resulted in the Department of Homeland Security was so politically difficult. ${ }^{129}$ These dynamics tend to freeze in place existing allocations of policymaking power and to disable reform proposals that would move authority away from some government agencies and give it to others.

In light of the political phenomena described here, it is tempting to simply acquiesce in the inevitability of the existing distribution of agency responsibility. But, major exogenous shocks can make substantial reorganizations politically possible (if not inevitable) - at which point the other six factors become more important in determining the allocation of responsibilities among the various bureaus, commissions, agencies, and departments that make up the United States government. Finally, the simple fact there is an ongoing demand for reorganization, even in the absence of major exogenous shocks, means that these issues are constantly in play. No one ever permanently surrenders, and there is no final judgment rule enforced on the disputants. ${ }^{130}$

\section{What Matters Most?}

${ }^{128}$ This episode is described in greater detail in William E. Kovacic, Antitrust in HighTech Industries: Improving the Federal Antitrust Joint Venture, 19 George Mason L. Rev. 1097, 1111-12 (2012). See also Hyman \& Kovacic, supra note 15.

${ }^{129}$ Even after the politics made reorganization inevitable, individual Congressional committees insisted on retaining regulatory oversight of "their" part of DHS. See Tumulty \& O'Keefe, supra note 30 at AQ ("the members of Congress overseeing [the agencies that were merged into DHS] were loath to give up any authority. That is why DHS gets marching orders from more than 100 congressional committees and subcommittees - a number that has grown in the past seven years, despite the 9/11 Commission's recommendation that those tangled lines of authority be consolidated.")

${ }^{130} \mathrm{Cf}$. Wilson, supra note 20, at 299-300 ("Public policy making in Europe is like a prize-fight: two contenders, having earned the right to enter the ring, square off against each other for a prescribed number of rounds; when one fighter knocks the other one out, he is declared the winner and the fight is over. Policy-making in the United States is more like a barroom brawl: Anyone can join in, the combatants fight all comers and sometimes change sides, no referee is in charge, and the fights last not for a fixed number of rounds but indefinitely or until everybody drops from exhaustion. To repeat former Secretary of State George Shultz's remark, 'its never over."') 
We believe that three factors matter most in predicting the long-term success of any given agency design: political implications, coherence, and capacity/capability -with political support, or the lack thereof the most important factor. An agency is doomed if it lacks a supportive constituency, or if the performance of its duties generates crippling political opposition. ${ }^{131}$ More broadly, an agency will not be able to operate effectively if its structure raises serious doubts about its legitimacy or increases the vulnerability to political pressure that the performance of its duties will arouse.

The second most important factor is policy coherence. Greater coherence increases the likelihood the agency will define its aims more clearly, set priorities and design programs appropriately, and develop a well-recognized brand. Coherence makes it easier to recruit qualified staff and build the necessary capacity to implement whatever programs are prioritized. An agency with policy coherence is accordingly better able to establish its credibility with external audiences, including the legislators who will determine funding and otherwise oversee agency operations.

The third most important factor is the agency's capacity/capability to perform its assigned functions. A severe mismatch between the commitments in an agency's policy portfolio and its capacity and capability to deliver results is likely to result in highly visible failures, of which Congress is usually quite unforgiving. Agencies with an inadequate talent pool and frail resources are more likely to generate poorly conceived programs, and less likely to execute tasks effectively. The mismatch between commitments and capacities creates a grim set of options. An agency can engage in policy triage, in the hope there will be no disasters in the ignored policy space and that no one cares enough about the tasks that are being ignored to make a fuss. Alternatively, an agency can try to cover all the assigned responsibilities with the predictable consequence of doing few (if any) of them well.

Of course, these factors are not independent of one another: an agency is more likely to have the necessary resources (i.e., capability) if it has strong political supporters. An agency that slights or over-emphasizes a portion of its regulatory portfolio is skating on thin ice unless its political supporters are on board with that decision. Similarly, without policy coherence, an agency is less likely to attract and maintain political support in the first instance. Finally, there are further levels of complexity imbedded

${ }^{131}$ See, e.g., Norton Long, Power and Administration, 2 PubliC AdMinistration ReV. 257 (1949) ("There is no more forlorn spectacle in the administrative world than an agency and a program possessed of statutory life, armed with executive orders sustained in the courts, yet stricken with paralysis and deprived of power, an object of contempt to its enemies and of despair to its friends. The lifeblood of administration is power.") 
within each of the factors. ${ }^{132}$

Our typology raises other difficult questions. Are all of the factors scalable? Are any of them? Can one compensate for weakness on one factor with strength on another? Does one need a minimum quantum of all of the factors to get off the launching pad? And so on. These issues must await better data and require further research. We now turn to the application of our 7-part framework to the CFPB.

\section{Application of Our Framework to the CFPB}

Before Dodd-Frank, numerous federal and state agencies shared regulatory responsibility for financial services. ${ }^{133}$ The regulatory status quo resembled a century-old house that had passed through several owners; each made changes to suit her tastes in architecture. Every new modification took place without apparent concern for the quality of the entire structure. The result was a jarring collision of styles that combined a colonial frame, some Victorian turrets, a Cape Cod extension, and a modernist wing of glass and steel.

The fragmentation of regulatory authority may have helped cause (and may even have worsened) the 2008 financial crisis. ${ }^{134}$ Reform could have taken several different paths. The least disruptive approach would have given existing agencies new authority and created stronger interagency coordination mechanisms. ${ }^{135}$ A bolder solution would have enhanced substantive regulatory controls and consolidated regulatory functions in a one public entity. Many observers who had studied the existing regulatory framework and its failings preferred to replace the existing regime with a clean design - or at least merge the SEC and CFTC. ${ }^{136}$

\footnotetext{
${ }^{132}$ For example, capacity is obviously affected by the allocated budget, but does it make a difference if the agency is funded with user fees $v$. dedicated taxes $v$. general appropriations? To what extent does the mix of funding among these choices reflect the impact of other factors - most importantly, political support?

${ }^{133}$ The federal regulators were Commodities Futures Trading Commission, two Treasury Department entities (the Office of the Comptroller of Currency and the Office of Thrift Supervision), the Federal Deposit Insurance Corporation, the Federal Reserve Board, the Federal Trade Commission, the National Credit Union Administration, and the Securities and Exchange Commission.

${ }^{134}$ The issue is contested, but this view was certainly shared by a majority of Congress. Senate Report No. 111-175, at 11 (2010).

${ }^{135}$ On this possibility. see William E. Kovacic, The Consumer Financial Protection Agency and the Hazards of Regulatory Restructuring, Lombard Street 19, 25 (Sept. 14, $\begin{array}{ll}2009) & \text { (hereinafter } \\ \text { http://www.ftc.gov/speeches/kovacic/090914hazardsrestructuring.pdf }\end{array}$

${ }^{136}$ See e.g., Steven Rattner, Regulate, Don't Split Up, Huge Banks, N.Y. Times A23 (Aug. 1, 2012) (criticizing Dodd-Frank's limited simplification of financial services
} 
Dodd-Frank did more than simply give existing agencies more powers, but it rejected a complete simplification of the regulatory status quo. Instead, the 2010 reforms took a minimalist path. Dodd-Frank retained all but one existing financial services regulator (OTS was shuttered and its responsibilities reallocated), while creating a new entity focused on consumer credit (the CFPB). ${ }^{137}$ Even this partial renovation provoked divisive debate. ${ }^{138}$

The CFPB originated in a 2007 article by (then-Professor and now Senator) Elizabeth Warren, who proposed creating a Financial Product Safety Commission. ${ }^{139}$ The article expressed no opinion about the new agency's optimal location and simply observed that "whether it is housed in a current agency like the CPSC or stands alone, the point is to concentrate the review of financial products in a single location, with a focus on the safety of the products as customers use them."140 A second article made a similar recommendation, while cautioning that agency capture was the "main regulatory design challenge." 141

Although most controversy focused on the CFPB's desirability, there was a parallel debate over where to place the agency in the

regulatory framework). But see David Zaring, With the Volcker Rule, the More Regulators the Merrier, N.Y. Times Dealbook, Dec. 9, 2013, at http://dealbook.nytimes.com/2013/12/09/with-the-volcker-rule-the-more-regulators-themerrier/? r=2 (noting that "even historical accidents have their merits).

${ }^{137}$ See John E. Villafranco \& Kristin A. McPartland, New Agency, New Authority: An Update on the Consumer Financial Protection Bureau, ANTITRUST SoURCE, Feb. 2012 (hereinafter Update), http://www.americanbar.org/content/dam/aba/publishing/antitrust_source/feb12_villafranc o_2_27f.authcheckdam.pdf; John E. Villafranco \& Kristin A. McPartland, New Agency, New Authority: What You Need to Know About the Consumer Financial Protection Bureau, ANTITRUST SOURCE, 2010, http://www.americanbar.org/content/dam/aba/publishing/antitrust_source/Dec10_villafranc o12_21f.authcheckdam.pdf.

138 See Daniel Carpenter, Institutional Strangulation, Bureaucratic Politics and Financial Reform in the Obama Administration, 8 PERSPECTIVES ON POLITICS 825 (Sept. 2010) (describing struggles over design of new financial services consumer protection institutions; Damian Paletta \& Deborah Solomon, Geithner Vents at Regulators as Overhaul Stumbles, WALL ST. J., Aug. 4, 2009, at 1 (recounting Treasury Secretary Geithner's criticism of various financial regulators for their opposition to plans to simplify regulatory framework); Treasury Plans Under Fire, WASH. Post, Aug 10, 2009, at http:/www.washingtonpost.com/wp-

dyn/content/article/2009/08/09/AR2009080902124.html (noting that President Obama left most regulators in place to avoid a protracted battle with the existing institutions).

${ }^{139}$ Elizabeth Warren, Unsafe at Any Rate, DEMOCRACY J. Summer, 2007, available at http://www.democracyjournal.org/pdf/5/Warren.pdf

${ }^{140} \mathrm{Id}$. at 18.

${ }^{141}$ Oren Bar-Gill \& Elizabeth Warren, Making Credit Safer, 157 U. PA. L. REV. 1, 99 n. 325 (2008). 
administrative state. Should the CFPB be an independent commission (similar to the FTC and CFTC)? If not, where did it belong - Treasury, Justice, the Federal Reserve? If located inside an existing public body, how independent should the CFPB be from traditional forms of oversight? $?^{142}$

Dodd-Frank put the CFPB inside the Federal Reserve, but insulated the bureau from oversight by almost everyone in the federal government. ${ }^{143}$ The CFPB's head is a single director appointed to a five-year term by the president and confirmed by the Senate. ${ }^{144}$ The president may remove the director for "inefficiency, neglect of duty, or malfeasance in office." "145 The CFPB operates outside the congressional appropriations process; it funds its operations with fees collected by the Federal Reserve - up to twelve percent of all fees the Fed receives. ${ }^{146}$ CFPB rulemaking is overseen by the Financial Services Oversight Committee (FSOC), which consists of representatives from several government agencies, including the Fed. ${ }^{147}$ The FSOC can overrule the Bureau's rules by a vote of two-thirds of its members, but can not influence or limit testimony by CFPB personnel, or overrule a decision by CFPB to bring an enforcement proceeding.

Many individual features of the CFPB are not unique. Other regulators with broad powers, such as the Environmental Protection Agency, are led by a single administrator. For some regulatory bodies headed by one person, the director is appointed to a fixed term and may be removed only for cause. ${ }^{148}$ Various financial services regulators also enjoy substantial autonomy from the budgetary appropriation process. ${ }^{149}$ But, the

${ }^{142}$ For a treatment of these issues, see Kovacic, Hazards, supra note 135.

${ }^{143}$ On these features, see Todd Zywicki, The Consumer Financial Protection Bureau: Savior or Menace? 81 Geo. Wash. L. Rev. 856 (2013) (hereinafter Savior or Menace). Dodd-Frank protects the CFPB from interference by its host institution (Federal Reserve). Under Title X of Dodd-Frank, the Fed shall not intervene in CFPB examinations or enforcement actions; appoint, direct, or remove any CFPB officer or employee; combine the CFPB or any of its functions with any other Federal Reserve unit; review, approve, or delay any CFPB rule or order; or review or approve any legislative testimony, recommendations, or comments of the CFPB director. Dodd-Frank $\S 1012(\mathrm{c})$.

${ }^{144}$ Dodd-Frank § 1011(b)(1). See Arthur E. Wilmarth, Jr., The Financial Services Industry's Misguided Quest to Undermine the Consumer Financial Protection Bureau, 31 Rev. Banking \& Fin. L. (forthcoming).

${ }^{145}$ Dodd-Frank $\S 1011(\mathrm{c})$.

${ }^{146}$ Id. For Fiscal Year 2013, the CFPB will receive nearly $\$ 600$ million. If the CFPB wishes to exceed the ceiling set in Dodd-Frank, it must seek a congressional appropriation.

${ }^{147}$ The FSOC has ten voting members: Treasury, CFPB, CFTC, FDIC, Federal Housing Finance Agency, the Fed, National Credit Union Administration, OCC, and SEC. Dodd-Frank $\S 1023$. The FTC is not on the FSOC.

${ }^{148}$ The Office of the Comptroller of the Currency is led by a single individual, the Comptroller of the Currency, who is appointed by the President for a five-year term, with the Senate's advice and consent. 12 U.S.C. $\S 2$.

${ }^{149}$ See Richard Scott Carnell, Jonathan R. Macey \& Geoffrey P. Miller, The Law of 
combination of protections afforded by Dodd-Frank makes the CFPB distinctive. And, the bundle of autonomy mechanisms, along with the independent-agency-within-an-independent-agency structure, gives the CFPB unmatched insulation from the accountability devices that limit other federal regulators.

The CFPB enforces numerous existing statutes (e.g., Equal Credit Opportunity Act, Fair Credit Reporting Act, Federal Debt Collection Practices Act, Home Ownership and Equity Protection Act, and Truth in Lending Act) that govern financial services for consumers. ${ }^{150}$ The bureau also received new statutory authority to challenge "unfair, deceptive, or abusive acts or practices" (UDAAP) involving consumer financial services. $^{151}$

In this section we benchmark the CFPB with the institutional factors set out in Section IV, supra.

\section{A. Policy Coherence}

The CFPB has substantial policy coherence. ${ }^{152}$ All CFPB policy assignments seek to protect consumers in financial services transactions. Its jurisdiction is broad and covers the extension of credit, the servicing of loans, the taking of deposits, real estate settlement services, check-cashing, stored payment card systems, collection services, financial advisory services, debt collection, and consumer credit reports. ${ }^{153}$ Congress gave the CFPB expansive authority to enforce the law, issue prescriptive trade rules, conduct on site examinations, provide guidance to firms and consumers, gather data, and issue reports.

There can be benefits from giving one regulator a wide array of related policy measures and implementation tools. At the same time, the breadth of tasks and tools creates its own perils. Each function creates a distinctive regulatory personality, ranging from prosecutor (enforcement actions) to cop on the beat (auditing and examinations) to teacher (consumer and business education), scholar (preparation of research

Banking and Financial Institutions $62\left(4^{\text {th }}\right.$ ed. 2009) (describing funding mechanism for the Federal Reserve).

${ }^{150}$ Dodd-Frank § 1002(14) defines "Federal consumer financial law" to include Title $\mathrm{X}$ of Dodd-Frank, eighteen federal consumer protection statutes enumerated in Dodd-Frank $\S 1002$ (12), and certain other laws. See also Villafranco \& McPartland, supra note 137, at $1 \&$ n. 5 .

${ }^{151}$ Dodd-Frank $\S \S 1022(\mathrm{~b}), 1031(\mathrm{~b})$.

${ }^{152}$ Dodd-Frank, Title X, $\S 1031(\mathrm{a}), 124$ Stat. at 2005. For a review of the CFPB's authority under Dodd-Frank, see Michael B. Mierzweski et al., The Dodd-Frank Act Establishes the Bureau of Consumer Financial Protection as the Primary Regulator of Consumer Financial Products and Services, 127 Banking 1.J. 722 (2010).

${ }^{153}$ Dodd-Frank, Title X, $\S \S 1002(5)$ \& 1002 (15), 124 Stat. at 1956, 1957-60. 
reports), information clearing house (credit card complaint database), and philosopher-king (rule-making). ${ }^{154}$ Each function is performed by employees with common training and values.

These discrete functions are likely to give rise to distinct departmental cultures, whose differences create internal tensions. Enforcement involves selective, ex post intervention and the identification of wrong-doers. Auditing entails continuing oversight and monitoring more akin to the operation of a public utility commission. The collection of industry data and preparation of reports draws upon the skills of researchers; these tools provide a decidedly more indirect (and, in some cases, more time-consuming) way of shaping policy than filing cases and issuing rules. ${ }^{155}$ The challenge for the CFPB is to develop and maintain an internal structure and culture that maximizes the complementarities across this range of policy tools, while minimizing the possible inconsistencies. Other agencies have had difficulty managing this dynamic. ${ }^{156}$

The CFPB's placement within the Fed scores less well on policy coherence grounds. The Fed focuses on macroeconomic policy while the CFPB focuses on consumer financial services. The Fed mostly attracts attention when it changes monetary policy, while the CFPB is likely to attract attention with every major case it brings, and every major rule it announces. ${ }^{157}$ We do not slight the public scrutiny drawn to the Fed's routine exercise of its powers, but we believe the CFPB will attract substantially more attention. External observers will have frequent reason to question the coherence and relatedness of Federal Reserve and CFPB programs considered as a single package.

\section{B. Branding and Credibility}

${ }^{154}$ The CFPB's power to issue regulations appears in Dodd-Frank $\S \S 1002(b), 1031$ (b), 1032 (a). The agency's law enforcement powers are enumerated in Dodd-Frank $\S \S$ 1002(12), 1031, 1036(a) (1) (B), 1052-55. The CFPB's examination and supervision mandates are set out in Dood-Frank $\S 1026$.

${ }^{155}$ The CFPB resembles the FTC's combination of law enforcement, rulemaking, and research functions. On the operation of the FTC's research function and its relation to the Commission's other policy implementation tools, See William E. Kovacic, The FTC at 100: Into Our 2d Century (Federal Trade Commission, January 2009) (hereinafter FTC at 100).

${ }^{156}$ Experience at the FTC has demonstrated that the realization of synergies and the exploitation of complementarities does not take place automatically. Id.

${ }^{157}$ On the public attention generated by the exercise of the Fed's macroeconomic policy role, see Age shall not weary her, The Economist, Dec. 21, 2013,d at 97; Peter Coy, The Fed's Overexposure Problem, Bloomberg Bus. Wk, Sept. 9-15, 2013. On the prominence of the CFPB's policy initiatives, see Danielle Douglas, New rules are set to curb abuses by mortgage servicers, Wash. Post, Jan. 17, 2013, at A15 (describing announcement of proposed CPFB rules for mortgage lending). 
The assignment of policy responsibilities can affect the agency's "brand" and determine the respect it receives from external constituencies. A strong brand assists an agency in obtaining healthier budgetary appropriations from Congress and in gaining greater deference from reviewing courts. ${ }^{158}$ Dodd-Frank gave the CFPB a strong brand (consumer advocate against abusive financial practices), and the Obama Administration has promoted that brand (and emphasized its impact for middle class consumers) for the past three years. ${ }^{159}$ The high interrelatedness of the CFPB's regulatory responsibilities and its consistency of purpose will help the CFPB achieve a coherent, wellrecognized brand.

The same clarity and consistency of the bureau's brand also poses risks. The CFPB is likely to experience a steady diet of consumer protection cases involving unfair, deceptive, and abusive conduct. Repeated exposure to business misconduct, coupled with a mandate to attack apparent episodes of illegal behavior aggressively, could lead CFPB personnel to develop a "shoot first, ask questions later" approach to enforcing Dodd-Frank. ${ }^{160}$

One way to avoid this problem is to build institutional structures that counteract path dependent habits that inflexibly incline professional staff to favor intervention. At the FTC, for example, the Commission receives recommendations on consumer protection cases not only from case handlers within the Bureau of Consumer Protection but also from the Bureau of Economics. ${ }^{161}$ This approach discourages consumer protection case handlers from overlooking regulatory costs and ignoring the role of competition and market-based responses in protecting consumer interests. Because attorneys know the Bureau of Economics will critique their before

${ }^{158}$ See William E. Kovacic, Creating a Respected Brand: How Competition Agencies Signal Quality, Antitrust L. J. (forthcoming, 2014).

${ }^{159}$ See President Barack Obama, Remarks by the President at Signing of Dodd-Frank Wall Street Reform and Consumer Protection Act, (July 21, 2010), at http://www.whitehouse.gov/the-press-office/remarks-president-signing-dodd-frank-wallstreet-reform-and-consumer-protection-act; (CFPB is "a new consumer watchdog with just one job: looking out for people - not big banks, not lenders, not investment houses looking out for people ... as they interact with the financial system"); Nikki Sutton, President Obama Nominates Richard Cordray to Lead Consumer Financial Protection Bureau, White House Blog (July 18, 2011, at http://www.whitehouse.gov/blog/2011/07/18/president-obama-nominates-richard-cordraylead-consumer-protection-bureau ("[W]e are going to stand up this bureau and make sure it is doing the right thing for middle-class families all across the country.")

${ }^{160} \mathrm{Cf}$. Wild, Wild West (1999) ("And you West, not every situation calls for your patented approach of "shoot first, shoot later, shoot some more and then when everybody's dead try to ask a question or two.") Similar concerns have been expressed about the IRS, where a steady diet of tax evaders can persuade IRS agents that everyone is a tax evader.

${ }^{161}$ Hyman \& Kovacic, Divide or Conquer, supra note 15, at 9 
the Commission, FTC consumer protection attorneys must acknowledge economic considerations in recommending cases. ${ }^{162}$

The CFPB has created an economic research unit and has hired economists with expertise in mortgage markets and consumer borrowing decisions. What role will the economists will play in shaping the new agency's culture and programs? The CFPB might use economic research to discipline law enforcement and rulemaking. ${ }^{163}$ By doing so, the agency could resist excessive exuberance for intervention. ${ }^{164}$ By contrast, the agency might treat its economists as subordinate to the attorneys who draft rules and prepare cases. These are notably different conceptions of role of economists in a regulator with law enforcement and rulemaking powers.

One sign of the future direction of the CFPB economists is staffing. The CFPB hired a prominent behavioral economist (Sendhil Multainathan) as its first Assistant Director of Research. Many behavioral economists believe insights from research in consumer psychology justify expansive regulatory intervention into financial services markets. ${ }^{165}$ Those who are skeptical about the implications of behavioral economics for regulatory intervention hotly contest this view. ${ }^{166}$ The CFPB's hiring process will determine whether such skeptics are welcome within the agency. If the agency defines the role of economists as providing support for intervention, skeptics are unlikely to apply for positions in CFPB, and if they do, unlikely to stay long enough to influence decisions. ${ }^{167}$ Law enforcement agencies that fail to provide a home for at least some skeptics are vulnerable to group-think, tunnel vision, empire building, and other regulatory

${ }^{162}$ Luke Froeb et al, The Economics of Organizing Economists, July, 2008, at http://ssrn.com/abstract=1155237.

${ }^{163}$ The CFPB has three principal operating units: Consumer Education \& Engagement; Research, Markets \& Regulation; and Supervision, Enforcement, Fair Lending \& Equal Opportunity. CFPB, Organization Chart, http://www.consumerfinance.gov/the-bureau/. There is a Research group within "Research, Markets \& Regulation." For a doubtful view that the CFPB will replicate the quality control provided by the FTC's economists, see Zywicki, Savior or Menace, supra note 143, at 899-917.

${ }^{164}$ The Bureau of Economics performs this quality control function at the FTC. See Froeb et al., supra at 162 (discussing influence of economists on FTC decisions).

${ }^{165}$ Not coincidentally, the prominent behavioral economist hired by the CFPB shares this view. See Michael S. Barr, Sendhil Mullainathan, and Eldar Shafi, Behaviorally Informed Financial Services Regulation, New America Foundation (2008), at http://www.newamerica.net/files/naf behavioral v5.pdf

${ }_{167}^{166}$ See Zywicki, Savior or Menace, supra note 143.

167 See Free to Choose? A Symposium on Behavioral Economics, at http://truthonthemarket.com/free-to-choose-symposium/. See also Niclass Berggren, Time for behavioral political economy? An analysis of articles in behavioral economics, Rev. Austrian Econ. 1 (2012); Mario Rizzo \& Glen Whitman, The knowledge problem of the new paternalism, 4 BRIGHAM Young U. L. REV. 905, 911 (2009). 
pathologies. ${ }^{168}$ These risks are pronounced for the CFPB, given the breadth of its substantive mandate, its powerful implementation tools, and the absence or relaxation of institutional controls that constrain other regulatory bodies. ${ }^{169}$ In these circumstances, the strong brand created by Dodd-Frank may turn out to be a weakness.

We noted earlier the potential spillover effects of the CFPB's operations on the Fed's brand. The CFPB's policy portfolio and implementing tools entail departures in form and degree from the Federal Reserve's historical role in financial services. The CFPB's performance of its responsibilities, good and bad, could blur the Fed's efforts to brand its work as a monetary policy technocracy. Even if the CFPB's brand achieves great clarity and wide public recognition, the clarity of the Fed's brand may be diluted.

C. Capacity and capability

As described earlier, capacity refers to the pool of knowledge and resources at the agency's disposal, and capability refers to the strength of formal powers and range of policy instruments. Because the CFPB has not yet made enough substantive decisions for us to have a view on its performance, we focus on capacity, and the other enabling legislation aspects of capability.

We have already observed that the CFPB possesses a formidable array of policy tools with which to accomplish its aims - meaning capability is unlikely to be a serious problem. Does CFPB have the human resources to accomplish these tasks? At first glance, it would appear that the CFPB will enjoy relatively generous resources. For FY 2013, the funding formula created in Dodd-Frank makes roughly $\$ 450$ million available to the new institution. ${ }^{170}$

One might think that the seemingly generous allotment of resources means that capacity will not be a serious problem. But, Dodd-Frank created

\footnotetext{
${ }^{168}$ The dangers of group think and tunnel vision for the CFPB are discussed in Zywicki, Savior or Menance, supra note 143, at 875-86. The impulse of public institutions to expand their size and influence (empire building) is described in Wilson, Bureaucracy, supra note 20 , at $179-81$.

${ }^{169} C f$ Richard Thaler, Level Playing Fields, in Soccer and Finance, N.Y. TIMES BU5 (July 25, 2010) ("Consider the Consumer Financial Protection Bureau now being established. Above all, I'd urge the head of this agency to devise rules under the assumption that, someday, he or she will be succeeded by a nitwit.") (emphasis supplied). Ramseyer has made a similar argument regarding judges. J. Mark Ramseyer, Not-soOrdinary Judges in Ordinary Courts: Teaching Jordan v. Duff \& Phelps, Inc., 120 HARV. L. REV. 1199, 1205-1207 (2007).

${ }^{170}$ Office of Mgmt. \& Budget, Other Independent Agencies 1296 (2012), available at http://www.whitehouse.gov/sites/defai;t/files/omb/budget/fy2013/assets/oia.pdf. See also http://files.consumerfinance.gov/f/2012/02/budget-in-brief.pdf
} 
an extraordinary rulemaking burden at the same time the CFPB was opening its doors. In its first year alone, CFPB was charged with issuing 24 rules. ${ }^{171}$ Some rules are ministerial, while others involve complex matters of policy and procedure. ${ }^{172}$ Issuing this many rules during a year would place a severe strain on even the most well established agency, but imposing that obligation on an agency during its start-up period invites disappointment. The struggle to complete a hopelessly unrealistic agenda of tasks is an invitation for error in the formulation of specific legal commands. Some rules have been put off, while the deadlines for others have slipped. ${ }^{173}$ Rules that are completed are unlikely to receive the quantity and quality of attention they would get if CFPB's rule-making process were not as overloaded. Affected parties which will challenge the rules no matter what they say will now have additional grounds for doing so (i.e., the issued rule did not adequately consider the costs and benefits of various alternatives because CFPB was overwhelmed). ${ }^{174}$ The CFPB had no role in creating the impossible mandates, but the inevitable efforts to postpone implementation or to seek extensions of statutory deadlines can hurt the agency's brand.

On the whole, the CFPB has fared relatively well in digging out from under the avalanche of duties imposed by Dodd-Frank. Through a form of regulatory triage the CFPB phased in some operations immediately and delayed others. The new agency front-loaded the promulgation of procedural rules that described how it will carry out its responsibilities. ${ }^{175}$ The agency also initiated a variety of public education programs ${ }^{176}$ and established a database for consumer complaints involving credit cards and transactions associated with mortgages, student loans, and bank accounts. ${ }^{177}$

At first, the CFPB largely "outsourced" enforcement functions to other government bodies (such as the FTC) with shared authority to implement financial services statutes involving practices such as debt collection. ${ }^{178}$ Over the past twelve months, the agency has accelerated the

${ }^{171}$ Davis Polk, Summary of the Dodd-Frank Wall Street Reform and Consumer Protection Act, Enacted into law July21, 2010, at i-ii (July 21, 2010).

${ }^{172} \mathrm{Id}$

${ }^{173}$ Davis Polk, Dodd-Frank Progress Report (January 2014).

${ }^{174}$ Our prediction here is based on experience at the FTC, where the effort to complete large numbers of complex trade regulation rules in the 1970 s led to severe problems with quality control. The FTC's rulemaking experience in the 1970s is examined in Sidney Milkis, The Federal Trade Commission and Consumer Protection: Regulatory Change and Administrative Pragmatism, 72 Antitrust L.J. 911 (2005).

${ }^{175}$ Davis Polk, Dodd-Frank Rulemaking Progress Report (Apr. 2011).

${ }^{176}$ Perhaps the most notable measure is the agency's "Know Before You Owe" campaign to assist consumers to understand the consequences of incurring debt.

${ }^{177}$ Davis Polk, Dodd-Frank Rulemaking Progress Report (Apr. 2011).

${ }^{178}$ J. Reilly Dolan, Acting Deputy Director, Bureau of Consumer Protection, The FTC 
tempo of its own enforcement program, announcing the prosecution of new cases (some in its own right, others in partnerships with other public agencies) and the opening of investigations. ${ }^{179}$ The principal early objects of CFPB enforcement have been credit card issuers. In 2012, the agency reached settlements with American Express, Capital One, and Discover to resolve charges of misleading sales tactics and obtained restitution totaling over $\$ 425$ million. ${ }^{180}$ Other focal points for cases and investigations within the past twelve months have included debt relief service providers, mortgage lenders and brokers, mortgage insurers, and providers of student loans.

In its rulemaking activities, the CFPB has continued to issue rules that describe how it will exercise its authority ${ }^{182}$ and more recently has begun to issue rules that elaborate substantive standards. ${ }^{183}$ It seems likely that CFPB will struggle with the rule-making process for a few years, and will not be fully operational, in the sense of executing all of its assigned functions for some time.

This dynamic poses risks to the stability of the political constituency that backed CFPB so enthusiastically in the first place. When the National Highway Traffic Safety Administration failed to deliver on the high Congressional expectations that inspired the enabling legislation in the first place, the agency's supporters took the lead in savaging its performance. One prominent sponsor suggested that responsibility for automotive safety should be given to NASA. ${ }^{184}$

The CFPB's efforts to sequence the execution of its assigned duties do not affect the capabilities or capacity of the Fed. However, missed deadlines, postponements, and other implementation delays are ordinarily taken as signs of poor agency performance, no matter how unrealistic the

and CFPB on Consumer Protection (May 2013).

${ }^{179}$ David Nather, A Fledgling Consumer Board Branches Out, Politicopro, Mar. 25, 2013 , at 8 .

${ }^{180}$ CFPB Press Release, CFPB Probe into Capital One Credit Card Marketing Results in \$140 Million consumer Refund (July 18, 2012); CFPB Press release, Federal Deposit Insurance Corporation and CFPB Order Discover to Pay \$200 Million Consumer Refund for Deceptive Marketing (Sept. 24, 2012); CFPB Press Release, CFPB Orders American Express to Pay $\$ 85$ million Refund to Consumers Harmed by Illegal Credit Card Practices (Oct. 1, 2012).

${ }^{181}$ Nather, supra note 179; Joe Prior, The Bitter Battle over The New Mortgage Rules, Politocopro, Mar. 25, 2013, at 16.

${ }^{182}$ See, e.g., CFPB Press Release, Consumer Financial Protection Bureau to Oversee Debt Collectors (Oct. 24, 2012) (describing methods for supervision of debt collectors with more than $\$ 10$ million per year in consumer debt collection).

${ }^{183}$ For example, in January 2013 the CFPB issued new rules on residential mortgages. Prior, supra note 181, at 16.

${ }^{184}$ Jerry Mashaw \& DAVId Harfst, The StrugGle For Auto SAFETy 108 (1990). 
initial allocation of tasks by Congress. The stigma of failed execution attaches to the agency, not the legislators who think that effective implementation consists of simply telling a bureau to "make it so." If the CFPB acquires a reputation for missing performance targets, the Federal Reserve's reputation for administrative competence could be collateral damage.

D. Collateral Effects Upon the Regulatory Ecosystem

The CFPB's creation will have several distinct collateral effects on the financial services regulatory ecosystem. For the most part, these effects will increase the cost of carrying out Dodd-Frank's commands or impede the realization of the statute's aims. In ways that received little evident attention in the legislative process, these collateral effects promise to diminish the CFPB's effectiveness and degrade the performance of other institutions with responsibilities for financial services regulator.

Coordination Costs. One major consequence of Dodd-Frank will be an increased need for inter-agency coordination. Congress consolidated some regulatory functions but left a substantially decentralized policy making system in place. As it established the CFPB, Dodd-Frank also created new supervisory machinery - the FSOC -- to give other financial services regulators some control over the CFPB's rule making activity. ${ }^{185}$

Decentralization means that a significant amount of policy integration will need to take place by "contract" (inter-agency coordination) rather than "ownership" (merging all regulatory functions into one entity). As discussed earlier, coordination costs usually are hidden from sight in the adoption of statutes. Where agencies have common policy boundaries or concurrent authority, new legislation ordinarily assumes that cooperation will be frictionless and costless, but that assumption is simply wrong.

The CFPB shares authority with other public agencies. ${ }^{186}$ Shared policy domains inevitably require the agency occupants to expend resources to cooperate and coordinate policy decisions. The formation of the FSOC and the exercise of its supervisory functions over the CFPB also will entail

${ }^{185}$ Dodd-Frank $\S \S 1022-23$. Dodd-Frank bars the CFPB from promulgating any rule unless it first consults with federal banking regulators and other appropriate federal agencies about the proposed rule's consistency with "prudential, market, or systemic objectives administered by such agencies." Dodd-Frank $\S \S 1022(b)(2) B), 1031(3)$. The FSOC may set aside all or part of a CFPB regulation if two thirds of the committee's members determine that "the regulation or provision would put the safety and soundness of the United States banking system or the stability of the financial system of the United States at risk." Id. at $\S 1023(\mathrm{a})$, (c) (3).

${ }^{186}$ For example, the CFPB shares enforcement responsibility with the Department of Housing and Urban Development with respect to mortgage financing for individuals with low incomes. 
administrative expense and an expenditure of management and staff time.

To some extent, the migration of personnel from the FTC to the CFPB - discussed below - facilitates policy cooperation. By absorbing FTC personnel, the CFPB will better understand the FTC's culture and operations and can use personal relationships to accomplish coordination tasks. FTC alumni now employed at the CFPB will be able to use personal ties with former colleagues still at the FTC to devise common solutions to shared policy tasks. The pre-existing personal bonds can serve to build a constructive CFPB-FTC relationship.

Dodd-Frank directs the CFPB and its federal counterparts to enter memoranda of understanding to organize their affairs. In January 2012, the CFPB and the FTC signed an MOU to coordinate enforcement efforts for shared duties for consumer financial products and services, ${ }^{187}$ and CFPB has negotiated MOUs with other federal agencies. ${ }^{188}$ Under their MOU, the CFPB and the FTC have cooperated on a number of projects, including the performance of a joint "sweep" of mortgage advertisements and the preparation of a joint roundtable on debt collection. ${ }^{189}$

Despite these coordination initiatives, the Dodd-Frank allocation of authority seems to have created tensions between the CFPB and the FTC. Over the past year, the CFPB has announced plans to require banks to exercise greater scrutiny of loan terms for automobile purchase contracts. There have been reports that the FTC has complained to the CFPB about what the Commission views as an encroachment upon its authority for automobile credit transactions. ${ }^{190}$ It remains to be seen how smoothly such issues will be handled going forward.

Dodd-Frank does not command the CFPB to enter MOUs with state governments. State governments retain considerable ability to determine the obligations that various financial services providers must fulfill. DoddFrank contemplates that the states and the CFPB will voluntarily establish formal or informal arrangements to coordinate law enforcement and other policy measures. An MOU may provide a useful platform for cooperation,

187 Consumer Protection Financial Bureau \& Federal Trade Commission, Memorandum of Understanding (2012), http://www.ftc.gov/os/2012/01/120123ftc-cfpbmou.pdf.

${ }^{188}$ See Building the CFPB, 11 (Coordination with Other Entities), July 18, 2011, at http://files.consumerfinance.gov/f/2011/07/Report BuildingTheCfpb1.pdf

${ }^{189}$ The focal points of CFPB/FTC coordination have been to ensure that the agencies know what each other is doing, achieve consistency in enforcement and policy, curb needless duplication of effort, avoid crossing wires on law enforcement investigations, and avoid double-teaming of respondents. See Dolan, supra note 178. The agencies have committed themselves to notify each other when opening investigations and filing cases

${ }^{190}$ We base this on discussions with FTC officials who have dealt with the CFPB on the auto-financing issue. 
but even these instruments are not self-executing. Those involved will need to exert considerable effort to create and sustain cooperative relationships, which will place further pressure on the CFPB's capacity.

One seldom goes wrong in overestimating the amount of effort that agencies must devote to building collaborative mechanisms that work well in practice. Dodd-Frank reveals no awareness that this process is neither instantaneous nor inexpensive. It is hard enough to establish strong interoperability and build a sense of common cause between only two government bodies. Dodd-Frank requires the CFPB to do so with a multitude of federal and state agencies.

Personnel Migration. Dodd-Frank also has a more direct impact on the regulatory ecosystem - specifically on the FTC. Dodd-Frank gives the CFPB exclusive authority to issue rules relating to the statutes it enforces, divesting the FTC of a longstanding role in this area. The CFPB also has more powerful remedies for the areas where it shares enforcement responsibility with the FTC. Dodd-Frank also enhanced the regulatory powers of other financial services regulators, such as the CFTC and the SEC.

The FTC competes with the CFPB for the same pool of lawyers, economists and administrative professionals with expertise in consumer protection. All of these entities need individuals with knowledge of credit practices, facility in rulemaking and litigation, experience in public education, and the ability to perform research. Before Dodd-Frank was enacted, the Federal Trade Commission arguably had the most expertise in these areas. ${ }^{191}$

The CFPB pays substantially higher salaries than the FTC. The CFPB is not subject to the same civil service pay scale as most federal agencies, and they are able to pay over $30 \%$ more than the FTC pays its professionals and administrative staff. Thus, an FTC attorney whose earnings were capped at $\$ 155,000$ could earn over $\$ 200,000$ at the CFPB.

The CFPB's mandate makes lateral moves more attractive than they previously had been to FTC officials. Dodd-Frank expanded the alternatives available to FTC professionals with financial services expertise. The CFPB gave the FTC's consumer protection attorneys and economists the opportunity to do challenging financial services work with a substantial wage increase. For senior federal employees, the higher wage scale means an immediate improvement in current income, Moreover, because federal pensions typically are calculated on the basis of their top three years of earnings in the federal system, a move to the CFPB can mean several thousand dollars more each month of retirement income.

\footnotetext{
${ }^{191}$ The FTC's role in this area dates back to the 1960s with the adoption of the Truth in Lending Act and the early 1970s with the adoption of the Fair Credit Reporting Act..
} 
The effects of these disparities are already apparent. By our current calculations, over thirty senior FTC employees have moved to either the CFPB or the CFTC. This accounts for only a few percent of the FTC's total headcount, but that modest figure does not convey the significance of the migration. Those moving include some of the FTC's best personnel with skills valuable in performing financial services regulatory tasks. ${ }^{192}$ It is not as though the FTC is unable to hire new personnel to fill vacancies. In the current employment market, the FTC will receive hundreds of applications for each position it posts. Many applicants have exceptional credentials. What cannot be replaced at will is the know-how and institutional memory specific to the implementation of the FTC's responsibilities. This knowledge can be restored over time, but this is a long and costly process. The FTC could become a farm team for recruiters from the CFPB or the CFTC.

A regulatory ecosystem perspective makes it clear that we should account for both the gains to the financial services regulators and the losses to the FTC in evaluating the overall impact of Dodd-Frank. The migration of human capital was a foreseeable consequence of Dodd-Frank, yet lawmakers gave it no weight in their deliberations. ${ }^{193}$ Dodd-Frank may degrade the FTC's performance, yet the harm will occur in ways not immediately observable. The FTC will lose cases that it would have won, or fail to rebuff a legal challenge to all or part of a rule. The agency will forego certain projects that demand the highest skills because it lacks the means to carry them out successfully. The FTC must either accept an inevitable decline in its financial services work or reposition its program, based on the new credit practices authority granted the FTC by Dodd-Frank, and the residual authority that the FTC retains.

Federal Reserve Spillovers. The CFPB's establishment also may affect the Fed. Any effect on the ecosystem will be mediated through the reputation and branding factors described previously. If the CFPB formulates programs that are seen to be sensible and the political storms subside, the Fed's brand as a macroeconomic policy technocracy might be enhanced. If the CFPB's initiatives falter and political controversy persists, the CFPB may reduce its host's stature, and may subject it to the political

192 These observations are based on one of our (Kovacic's) familiarity with personnel changes at the FTC. Several examples stand out. Peggy Twohig is now a senior manager at the CFPB. She previously headed the FTC's credit practices unit in the Bureau of Consumer Protection. Twohig initially was seconded to the CFPB by the FTC and chose to remain. Others who joined the CFPB include Lucy Morris, the FTC's chief litigator in financial services cases and winner of the FTC's premier award for superior performance, and Jessie Leary, the FTC's leading consumer protection economist.

${ }^{193}$ One of us (Kovacic) met with repeated indifference in attempting to press this issue with the relevant legislative committees. 
winds from which it has long been insulated. Sustainable?

E. Resilience: Is the Assignment of Functions Adaptable and

Dodd-Frank's assignment of responsibilities to the CFPB is adaptable and sustainable, as long as the CFPB does not overreach. The flexibility of the CFPB's mandate and the range of its policy tools will give the agency considerable ability to adapt to new circumstances. Perhaps the most important likely source of broad "scalability" is the Bureau's authority to proscribe behavior that is "unfair, deceptive, or abusive." The unfairness and deception elements of this command are modeled on Section 5 of the Federal Trade Commission Act, which authorizes the FTC to challenge "unfair or deceptive" acts or practices. ${ }^{194}$ The CFPB's mandate to reach "abusive" conduct supplies an invitation to reach behavior beyond the prohibitions on unfairness and deception

The FTC's experience shows both the promise and peril of scalable allocations of regulatory authority. The federal courts have declared that the FTC's unfairness authority under Section 5 of the FTC Act confers power to reach conduct not previously condemned by statute or judicial decisions. ${ }^{195}$ For example, the FTC's emergence as the principal federal enforcement body concerning data protection and privacy built upon the application of the Commission's unfairness authority. ${ }^{196}$

The FTC's history also demonstrates that the application of a highly scaleable mandate can create two distinct traps. First, legislators and other external observers come to regard the agency as a solution for all problems that have an apparent connection to the expansive mandate. Congress will urge an agency with an elastic mandate to forbid "unfair" conduct to take steps to reduce prices for products such as gasoline, even though no measures within its control will be effective, and efforts to intervene (e.g., to attack price rises as "price-gouging") may retard market responses that eventually cure the problem. ${ }^{197}$

Second, an agency with a sweeping, adaptable mandate has incentives to extend the boundaries of its authority, to show it is fulfilling the goals Congress set for it. Open-ended assertions of authority invite carelessness in implementation. Unless the agency exercises great

\footnotetext{
${ }^{194}$ See Wilmarth, supra note 144.
}

${ }^{195}$ Marc Winerman \& William E. Kovacic, Outpost Years for a Start-Up Agency: The FTC from 1921-1925, 77 Antitrust L.J. 145 (2010).

${ }^{196}$ Woodrow Hartzog \& Daniel Solove, The FTC and the New Common Law of Privacy, Colum. L. Rev. (Forthcoming 2014).

${ }^{197}$ See William E. Kovacic, Standard Oil Co. v. United States and Its Influence on the Conception of Competition Policy, 11 Competition L.J. 89, 103-08 (2012) (discussing congressional demands that FTC take steps to reduce gasoline prices). 
discipline, it will find it tempting and easy to expand claimed authority without rigorously testing the logic for intervention. These lapses eventually can provoke severe political backlash, and rebukes from reviewing courts. ${ }^{198}$

\section{F. Cohesion}

As described above, the CFPB's mandate involves coherent, highly interrelated policy making tasks. Were there to be intramural rivalry or tension, it likely would result from the diversity of policy making functions the CFPB must perform - i.e., among those charged, respectively, with bringing cases, issuing rules, performing research, carrying out audits, and providing public and business education. As noted previously, this phenomenon occurs at multiple agencies. Intramural competition for prestige and resources can cause agency officials to spend substantial effort refereeing disputes among rival divisions. These resources would otherwise be applied to serve program needs.

Intramural rivalry has other costs. Where individual operating units strive to create separate identities, personnel within those units may develop loyalty to their own unit and define success in terms of their unit's chievements. Projects requiring cooperation across units may appear relatively unimportant, or simply contrary to each group's interests, even though greater collaboration across units would advance projects that serve the larger aims of the entire institution. The CFPB may find it difficult to mobilize resources across units unless it can create a "we're all in this together" ethos.

That said, some dynamic tension across units can be helpful. As noted previously, the formulation of consumer protection policy at the FTC (including financial services) has been informed by the agency's economists. The Bureau of Economics (BE) is a voice for the value of competition, for the inclusion of market-oriented strategies in the mix of regulatory tools, and for awareness of costs of specific regulatory choices. $\mathrm{BE}$ also performs empirical research that has yielded major insights into how consumers perceive disclosures provided in financial services instruments. BE has helped instill within the FTC a culture that encourages ex post evaluation to measure the policy results of specific initiatives. It remains to be seen whether CFPB will create a similar framework - and whether a group likely to be dominated by intervention-minded behavioral

\footnotetext{
${ }^{198}$ The experience of the U.S. national intelligence agencies arguably illustrates this hazard. The National Security Administration relied upon an expansive mandate to embrace ever broader interpretations of its authority to monitor telecommunications transmissions. In doing so, it appears to have failed to impose internal safeguards to ensure that surveillance programs adhered rigorously to the limits of its statutory powers.
} 
economists will exercise a similar disciplining function.

What of the prospects for synergy between the CFPB and the Fed? Dodd-Frank sought to insulate the CFPB from the Fed, but there are considerable overlaps in substantive knowledge and expertise. The Fed has deep expertise in credit practices related to the CFPB's duties. Notions of CFPB autonomy might discourage effective interaction. Similarly, if CFPB personnel view the Fed suspiciously, owing to its perceived lapses in oversight before the financial crisis, cooperation is likely to be seen as a negative. We see the possibility for considerable gains from trade, but there are policy impulses that might discourage it.

\section{G. Political Implications}

As noted previously, the CFPB has broad authority, but Congress dispensed with many mechanisms it has used in the past to balance agency autonomy and accountability. The CFPB is headed by a single director, not a multi-member board consisting of individuals of diverse political affiliations. ${ }^{199}$ Congress also set aside the ritual of annual appropriations and made the Bureau a fee-funded body. It placed this autonomous unit within another government body, the Federal Reserve, which itself enjoys substantial insulation from the political accountability methods that govern other regulators. In general, Dodd-Frank contradicted settled practice of tying greater accountability to increases in an agency's power.

The CFPB was controversial to begin with, and the enactment of Dodd-Frank did not end debate about the wisdom of these institutional choices. For many months the White House declined to nominate a director. ${ }^{200}$ As a temporary expedient, President Obama assigned Professor Elizabeth Warren to manage the CFPB from a position located within the Department of Treasury. ${ }^{201}$ Warren had played a central role in designing the CFPB, and she had become a lightning rod for critics of the new body. Republicans in the Congress said they would not confirm Warren or any other nominee to be the CFPB's director without basic changes to the CFPB's institutional architecture. ${ }^{202}$ These included the removal of the CFPB from the Fed, its re-creation as a stand-alone, multimember regulatory commission, and the use of annual appropriations to fund its operations. In January 2012, President Obama nominated Richard Cordray,

${ }^{199}$ The choice of a single director raises questions about whether the CFPB is more vulnerable to capture because it may require only a single appointment to alter its direction (as opposed to the diversification afforded by a multi-member governance structure). Cite to commentary on this point.

${ }^{200}$ Deepak Gupta, The Consumer Protection Bureau and the Constitution, 65 Admin. L. Rev. 945 (2013).

${ }^{201}$ Id.

${ }^{202}$ Id. 
the former Attorney General of Ohio to the post. ${ }^{203}$ The nomination went nowhere because it was clear there were insufficient votes to overcome the promised filibuster.

President Obama sought to circumvent this obstacle by using a recess appointment. ${ }^{204}$ This move intensified the already rancorous debate about the new Bureau and inspired further debate about whether DoddFrank permitted a recess appointee to head the agency, and whether Congress was actually in recess when Cordray initially was appointed. ${ }^{205}$ As part of a larger legislative deal involving the NLRB, Cordray eventually received Senate confirmation in 2013 . $^{206}$

Upon taking office with his recess appointment, Cordray immediately announced that the CFPB would apply the enforcement and rulemaking powers granted by Dodd-Frank. The continuing political dispute over the CFPB poses two dangers to the new agency. The delay in appointing a director of any sort impeded the roll-out of the CFPB's program. Dodd-Frank specified that the Bureau could not perform certain functions until a director took office, ${ }^{207}$ and Cordray's delayed nomination, and recess appointment led to delays in CFPB coming on-line. This was a serious disadvantage for a body given an impossibly ambitious assignment of rulemaking and other start-up tasks.

The circumstances of Cordray's recess appointment in 2012 have created a latent liability for work performed by the CFPB until Cordray's confirmation in 2013. In January 2013, the U.S. Court of Appeals for the District of Columbia ruled that President Obama's appointments of three members of the National Labor Relations Board were constitutionally invalid. $^{208}$ In June the Supreme Court accepted certiorari to review the D.C. Circuit's decision. ${ }^{209}$ Affirmance of the court of appeals ruling could cast doubt upon the legitimacy of Cordray's appointment to the CFPB. If Cordray's appointment was invalid, there would be serious questions about the validity of actions taken - notably, the promulgation of rules - during the period of the Cordray's recess appointment. ${ }^{210}$

${ }^{203}$ Id.
${ }^{204}$ Id.
${ }^{205}$ Id.
${ }^{206}$ Id.
${ }^{207}$ Id.
${ }^{208} \mathrm{~N}$

${ }^{208}$ Noel Canning v. NLRB, 707 F.3d 400 (D.C. Cir. 2013). The challenged appointments to the NLRB were made on the same day as President Obama's recess appointment of Richard Cordray to the CFPB.

${ }^{209}$ The petition for certiorari was granted on June 24, 2013.

${ }^{210}$ Cordray's recess appointment has been challenged on the same grounds as those advanced by respondent in the NLRB case. The case is pending in the U.S. District Court for the District of Columbia. State National Bank of Big Spring v. Wolin, Case No. 1:12- 
There is a second danger to the CFPB if political disagreements over the future configuration and leadership of the agency are not resolved -even if the recess appointment of Cordray is ultimately upheld. No regulatory agency can prosper without an essential foundation of political support, and the CFPB faces an enormous challenge to build the political capital it will need to succeed. The active implementation of the Bureau's regulatory tools can be expected to create backlash of the sort that many regulatory agencies experience. On many occasions, Congress has granted broad, nominally powerful authority and then stepped forward to protect affected firms that complain about overly "aggressive" applications of that authority. $^{211}$ Every day of the week agencies collect or spend political capital. Without a positive balance to respond to future political attacks, the CFPB will find it difficult to build and maintain an effective program.

The rancorous political debate accompanying the birth of the CFPB does not bode well for its future. We expect many Republican members of Congress will jump on every opportunity to attack the CFPB, and use those opportunities to try and revisit the design choices made in Dodd-Frank. ${ }^{212}$ Even if formal changes are not forthcoming, various forms of equilibration are possible. Courts, for example, could choose to exercise more stringent review of CFPB rules, even while professing to adhere to standards mandated by the Administrative Procedure Act. Congress could choose to demand more frequent appearances by CFPB leadership to explain and defend the agency's programs. Congress also has many other ways to make life difficult for agencies that displease it, and the CFPB starts deep in the hole on that score. ${ }^{213}$

To date, the political brawl over the CFPB has not spilled over to the Federal Reserve. Whether disputes over the CFPB affects the Federal Reserve will depend greatly on two factors: the performance of the CFPB going forward, and the skill of the Federal Reserve in creating a distance between its core brand and the brand of its involuntary tenant.

cv-01032 (D.D.C.).

211 On the FTC's experience in this regard, see William E. Kovacic, The Federal Trade Commission and Congressional Oversight of Antitrust Enforcement, 17 Tulsa L. Rev. 587 (1982).

${ }^{212}$ See. e.g., Rob Blackwell, Why Ethics Charges Against CFPB Vet Raj Date are weak, American Banker, Aug. 5, 2013, at http:/www.americanbanker.com/issues/178 150/why-ethics-charge-against-cfpb-vet-rajdate-is-weak-1061115-1.html?pg=2 ("A fair number of Republicans hear the word CFPB and immediately start seeing hobgoblins and ghosts,' said Reginald Brown, vice chairman of the financial institutions practice group at WilmerHale and a former White House counsel during the Bush administration.")

213 See Wilmarth, supra note 144; William E. Kovacic, Competition agencies, independence, and the political process, in Competition Policy and the Economic Approach 291 (Josef Drexl et al. eds. 2011). 
H. Scoring the CFPB

How does the CFPB do on the factors we have identified? The CFPB does well on four factors (policy coherence; branding and credibility; resilience; cohesion), fares poorly on two (collateral effects on the regulatory ecosystem; political implications), and presents a mixed picture on one factor (capability/capacity). On the three factors that we have identified as most important, the CFPB does well on one (policy coherence), mixed on a second (capability/capacity), and poorly on the third (political implications).

It is far too early to draw conclusions about the performance of so young a government body, but we offer three tentative predictions. To be sure, there are no guarantees in life or in agency design -- luck, history, culture, and the decisions made by senior agency personnel, both at the outset and in moments of crisis, all play important roles, and will affect whether the CFPB becomes a durable part of the regulatory architecture for financial services.

First and most importantly, the CFPB's design builds in vulnerabilities that will likely prevent it from fulfilling the expectations of its creators. Second, the effort to insulate the CFPB from political interference will likely embroil it in recurring struggles with Congress over accountability for its policies, and may well spill over and damage the Federal Reserve. Third, the existence of the CFPB will likely undermine the effectiveness of the FTC.

\section{A Case Study of PPACA}

Dodd Frank was not the most significant legislative initiative of President Obama's first term. Far more significant was the Patient Protection and Affordable Care Act ("PPACA"), which mandated dramatic changes in the financing and delivery of health care in the United States. The challenges associated with PPACA's implementation provide a useful "real-time" case study that complements our analysis of the CFPB. Because we anticipate writing another article on the subject, we only sketch out a few of the issues here.

By common consensus, the roll-out of the website, www.healthcare.gov, has been a complete disaster. ${ }^{214}$ The website, which was intended to provide a seamless portal to the exchanges that were a

\footnotetext{
214 See, e.g., Ezra Klein, How the IPod President Crashed: Obama's Broken Technology Promise, Businessweek, Oct. 31, 2013, at http://www.businessweek.com/articles/2013-10-31/obamas-broken-promise-of-bettergovernment-through-technology\#p1 (referring to "disastrous launch," and "debacle").
} 
centerpiece of PPACA, crashed the instant it was launched. ${ }^{215}$ Top administration officials initially attempted to portray the website's failure as a success story, resulting from high demand and a few "glitches.",216 Eventually, the administration grudgingly acknowledged the problems, and promised to make the website "work smoothly for the vast majority of users" by the end of November, 2013. ${ }^{217}$

Since then, the performance of the front-end of the website has improved dramatically, but serious questions remain about a wide array of other issues, including the extent to which administration officials knew the website was not ready for prime time, while making public statements to the contrary; ${ }^{218}$ the quality of the information that is being provided to insurers after it is collected by the website; ${ }^{219}$ continued technical problems with the website ${ }^{220}$ the failure to build in robust security protections for the private health care information that is collected by the healthcare.gov website; ${ }^{221}$

215 The PPACA requires most uninsured Americans to secure health insurance coverage by registering with publicly-operated exchanges and selecting plans provided by various private insurance companies -- or, if they fall below an income threshold, by obtaining coverage through Medicaid.

${ }^{216}$ On October 1, 2013, Secretary Sebelius went on network television and said: "we have had a few slowdowns, a few glitches, but it's sort of a great problem to have. It's based on the fact that the volume has been so high and the interest is so high. We're working quickly to fix that." See http://www.youtube.com/watch? $v=Y Q 8$-InZH7LI/ See also Sharon Begley, Analysis: IT Experts question architecture of Obama website, Reuters, Oct. 5, 2012, at http://uk.reuters.com/article/2013/10/05/us-usa-healthcare-technologyanalysis-idUKBRE99407T20131005

${ }^{217}$ See Klein, supra note 214. See also Amy Schatz, Exchange Site Needs Hundreds of Fixes, Wall St. J., Nov. 7, 2013, at A6 ("There is no excuse for what has been a miserable six weeks") (quoting HHS secretary Kathleen Sebelius))

${ }^{218}$ Sandhuya Somaskehar, Glitches Noted ahead of Obamacare Launch, Wash. Post, Sept. 28, 2013, at A1; Stephanie Kirchgaessner, Congress told of website scramble, Financial Times, Oct. 25, 2013, at 6; Michael D. Shear \& Sheryl Gay Stolberg, In White House Pitches, Rosy View of Health Care Site, N.Y. Times, Oct. 24, 2013 at A14 ("Just days before HealthCare.gov went live with disastrous results, top White House officials were excitedly briefing lawmakers, reporters, Capitol Hill staff members and Washington pundits on their expectations for the government's new health care Web site. . . the fastpaced PowerPoint briefings showed images of a shiny new Web site that was elegantly designed, simple to use and ready for what officials hoped would eventually be a flood of customers on Oct. 1. One lawmaker recalled comparisons to Travelocity, the travel booking site.")

${ }^{219}$ See Stephanie Kirchgaessner, Contractor blames White House for 'Obamacare' exchange flaw, Financial Times, Oct. 24, 2013, at 2 (raising issues about accuracy of data collected by healthcare.gov website).

${ }^{220}$ Spencer E. Ante \& Louse Radnofsky, Three-Hour Outage Echoes Health Site's Flawed Launch, Wall St. J., Dec. 21-22, 2013, at A4.

221

See,

e.g.,

http://science.house.gov/sites/republicans.science.house.gov/files/documents/HHRG-113$\underline{\text { SY-WState-DKennedy-20131119.pdf }}$ 
the decision by the administration to overrule its internal privacy expert, and launch the website without the necessary security protections; ${ }^{222}$ and the refusal to release timely information on the number of people that have actually secured coverage through healthcare.gov. ${ }^{223}$ The website launch has not been the only implementation challenge; the administration has had to repeatedly announce delays and modifications to PPACA (often without explicit statutory authority). ${ }^{24}$ And, the states have faced implementation challenges of their own - which have been compounded by the ad hoc delays and modifications announced by the administration. ${ }^{225}$ Elected officials and commentators from across the political spectrum have harshly

${ }^{222}$ Sharyl Attkisson, High Security Risk found after HealthCare.gov launch, Dec. 20, 2013, at http://www.cbsnews.com/news/high-security-risks-found-after-healthcaregovlaunch/ ("Fryer told congressional interviewers that she explicitly recommended denial of the website's Authority to Operate (ATO), but was overruled by her superiors. . . Fryer says she briefed Sebelius' top information officers at HHS in a teleconference on Sept. 20, recommending the website's launch be delayed for security reasons.")

${ }^{223}$ Instead of providing actual enrollment figures, the administration has released information on the number of individuals who have selected a plan. It has also not released much in the way of demographic information on enrollees. For criticism of these strategies, see Seth Chandler, Coverage on January 1, 2014 matters, Dec. 24, 2013, at http://acadeathspiral.org/2013/12/24/coverage-on-january-1-2014-matters/ ("it is difficult to tell right now whether the ACA is performing as hoped. A few things are clear, however. The first thing is that the Obama administration is not releasing the sort of information from which an objective assessment could be made. Platitudes such as 'Millions of Americans, despite the problems with the website, are now poised to be covered by quality affordable health insurance come New Year's Day,' from President Obama at his last press conference are just not a substitute for knowing how many people have enrolled in the plans in the various Exchanges, and more importantly, have paid for coverage. What are their ages? How about some real numbers as a Holiday present?")

${ }^{224}$ See Robert Pear, U.S. again moves a health plan date, Int'1 N.Y. Times, Dec. 26, 2013, at 8 (reporting Obama administration announcement extending the application deadline for individuals who can show they missed earlier deadlines due to problems with the Obamacare website); Timothy W. Martin \& Christopher Weaver, Insurers Rattled by Tweaks To the Affordable Care Act, Wall St. J., Dec. 21-22, 2013, at A4 (recounting Obama administration's adjustments to PPACA deadlines). Other ad hoc decisions include the one-year delay in the employer mandate, and the "hardship" exemption from the individual mandate given to those who had prior coverage that was cancelled).

Such "government by waiver" creates obvious risks, including the perception that government policy is being set to reward political allies and punish opponents. See Louise Radnofsky \& Melanie Trottman, Health-Fee Proposal Knocked, Wall St. J., Nov. 7, 2013, at A6 (describing plans by HHS to exempt labor unions and business from reinsurance fee imposed by the PPACA); Richard Epstein, Government by Waiver, 7 National Affairs 39 (2011).

${ }^{225}$ See Sandhya Somashekhar \& Sarah Kliff, Sebelius assures fixes are being made, Wash. Post, Nov. 7, 2013, at A3, A4 (describing problems with state exchanges in California, Colorado, Oregon, and Vermont). 
criticized the website and the roll-out of PPACA. ${ }^{226}$

How did we find ourselves in this mess? The governmental design issues we analyze in this article played an important role. Immediately after PPACA was enacted, the Obama administration recognized that implementation would be challenging, and put together a "high level team" to implement what "one insider described as an "elaborate implementation plan.",227 One month later, an outside expert close to the administration (Professor David Cutler) sent a confidential memo to a senior administration official, warning that their implementation strategy was deeply flawed and likely to fail. ${ }^{228}$ More specifically, Cutler was very concerned that "the personnel and processes you have in placed are not up to the task, and that health reform will be unsuccessful as a result." 229 Cutler stated that "the early implementation efforts are far short of what it will take to implement reform successfully."230 More specifically, he wrote, "for health reform to be successful, the relevant people need a vision about health system transformation and the managerial ability to carry out that vision." 231 In bold-faced type, Cutler then wrote, "I do not believe the relevant members of the Administration understand the President's vision or have the capability to carry it out."232 For PPACA to work, the White House would have to set up "a new structure to focus on where it needs to go" and not to pile "new responsibilities onto a broken system."233

${ }^{226}$ See, e.g., Unstable condition, Washington Post, Dec. 22, 2013, at A22 (editorial criticizing HHS for "continued tinkering" with PPACA requirements and noting the resulting disruption); Going public, and private, The Economist, Dec. 21, 2013, at 91 (discussing "disastrous" launch of website); Somashekhar \& Kliff, supra note 225, at A4 (quoting Sen. Bill Nelson (D. Fl.) as telling HHS Secretary Kathleen Sebelius to hold those responsible for failed website roll-out accountable; Nelson said "I want you to burn their fingers and make 'em pay for not being responsible and producing a product that all of us could be proud of.").

227 Jackie Calmes, After Health Care Passage, Obama Pushes to Get it Rolling, N.Y. Times, Apr. 17, 2010, at A16. ("Mindful that the new health care law's ability to slow rising medical costs will depend to a great extent on how it is put in effect, President Obama is assembling a high-level team to carry out key elements of the overhaul and is considering moving faster than the law requires to put them into action.")

${ }^{228}$ Memorandum from David Cutler to Larry Summers, "Urgent Need for Changes in Health Reform Implementation" (May 22, 2010) (hereinafter "Cutler Memo"). A copy of the memo is posted as an online appendix to this article. The memo, and the underlying struggle over implementation is described in detail in Amy Goldstein \& Juliet Eilperin, Healthcare.gov: How political fear was pitted against technical needs, Wash. Post, Nov. 2 2013 , at 1 .

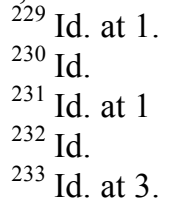


Cutler concluded with a call for urgent changes: "I strongly encourage you to make changes now, before you are too late to get the outcomes we need." 234

Cutler's memo provides his perspective on the institutional dynamics that resulted from the assignment of implementation responsibility for PPACA to HHS, and within HHS to the Centers for Medicare \& Medicaid Services. Indeed, Cutler identified this decision as "a central concern." 235 Cutler paints a dismal portrait of CMS: "the agency is demoralized, the best people have left, IT services are antiquated, and there are fewer employees than in 1981, despite a much larger burden."236 Cutler cuttingly continues, "you have an agency where the philosophy of health system reform is not widely shared, where there is no experience running a health care organization, and where the desire to move rapidly is lacking."237 Worse still, HHS and CMS displayed little understanding of what it would take to make the health care exchanges work properly. ${ }^{238}$

Cutler further observed that problems were not limited to the operational level:

The overall head of implementation inside HHS, Jeanne Lambrew, is known for her knowledge of Congress, her commitment to the poor, and her mistrust of insurance companies. She is not known for operational ability, knowledge of delivery systems, or facilitating widespread change. Thus, it is not surprising that delivery system reform, provider outreach, and exchange administration are receiving little attention. Further, the fact that Jeanne and people like her cannot get along with other people in the Administration means that the opportunities for collaborative engagement are limited, areas of great importance are not addressed, and valuable problem solving time is wasted on internal fights.

Cutler concludes his memo with recommendations for "a major change at HHS," including "a revamped and enhanced implementation group.",239 The new team would include individuals with expertise in managing large and complex enterprises, health care payment reform, information technology systems, outreach and education to reach health care providers and insurers, and state coordinators. ${ }^{240}$

\footnotetext{
${ }^{234}$ Id.

$235 \mathrm{Id}$. at 1.

${ }^{236}$ Id. at 2.

${ }^{237}$ Id. at 2 .

${ }^{238} \mathrm{Id}$.

${ }^{239}$ Id. at 3

${ }^{240}$ Id.
} 
The advice in Cutler's memo was ignored. Of course, Cutler was not focusing on the risk of website failure. And, even if the Administration had heeded Cutler's advice, there is no guarantee that the same problems (or other, more severe problems) would not have materialized. But, it is striking that Cutler's memo highlights the importance of two of the three factors that we have identified as most important (e.g., coherence and capacity/capability). And, it is equally striking that one of the proposed "fixes" now being considered for addressing the dysfunction of the federal health insurance marketplace is to transfer authority away from CMS to a "CEO-type figure with clear authority and knowledge of how insurance markets work.,"241

Cutler does not mention politics - the third of the three factors we have identified as most important. Politics would have created a hostile environment in which to launch PPACA even if the best management team in the world had been in charge of its implementation - which was clearly not the case. ${ }^{242}$ Only naked political calculation can explain the administration's decision to assign implementation responsibility for PPACA to CMS; to delay many of the implementation decisions and enabling regulations until after the 2012 election (and disclosure of some of those decisions, even when they had been made before the 2012 election); and to give upbeat presentations promoting the roll-out, and hide all evidence that things were not going well. ${ }^{243}$ Indeed, one prominent staffer

${ }^{241}$ David Morgan, U.S. Government Urged to name CEO to run Obamacare market, Reuters, Dec. 29, 2013 ("Advocates have been quietly pushing the idea of a CEO who would set marketplace rules, coordinate with insurers and state regulators on the health plans offered for sale, supervise enrollment campaigns and oversee technology, according to several sources familiar with discussions between advocates and the Obama administration. Supporters of the idea say it could help regain the trust of insurers and others whose confidence in the healthcare overhaul has been shaken by the technological woes that crippled the federal HealthCare.gov insurance shopping website and the flurry of sometimes-confusing administration rule changes that followed.")

${ }^{242}$ See Goldstein \& Eilperin, supra note 228 ("“They were running the biggest start-up in the world, and they didn't have anyone who had run a start-up, or even run a business,' said David Cutler, a Harvard professor and health adviser to Obama's 2008 campaign, who was not the individual who provided the memo to The Washington Post but confirmed he was the author. 'It's very hard to think of a situation where the people best at getting legislation passed are best at implementing it. They are a different set of skills."')

${ }^{243}$ See id. ("the project was hampered by the White House's political sensitivity to Republican hatred of the law - sensitivity so intense that the president's aides ordered that some work be slowed down or remain secret for fear of feeding the opposition. . . [the White House] slowed down important regulations that had been drafted within CMS months earlier, appearing to wait until just after Obama's reelection. Among the most significant were standards for insurance coverage under exchanges. The rules for these 'essential health benefits' were proposed just before Thanksgiving last year and did not become final until February. Another late regulation spelled out important rules for 
defended such tactics on political grounds: "Some Democrats said that, given the Republican assault on the measure, the White House was right to deliver upbeat presentations promoting it. 'To downplay expectations would have fed into the Republican narrative,' said Jim Manley, a former top aide to Senator Harry Reid of Nevada, the Democratic leader, who attended a session in the Roosevelt Room of the White House with other allies of the administration.",244

It is too early to tell how the political winds will affect the future of PPACA, and the agencies charged with its implementation. But, if PPACA cannot deliver on the promised benefits in short order, we predict the emergence of a (likely bipartisan) coalition for retooling (and maybe even repealing) large portions of the PPACA. The probability of this occurring is significantly higher if (i) the exchanges fail to enroll sufficient numbers of healthy individuals (which will trigger an increase in the cost of coverage, rather than the decrease repeatedly promised by President Obama), with consumers receiving notice of those rate increases immediately before the mid-term election in November, 2014; or (ii) large numbers of people lose their grandfathered coverage, and find the new coverage unsatisfying (either because it is too expensive, or because they are unable to continue seeing their preferred doctors); or (iii) there is a significant breach in the privacy of the information collected by healthcare.gov. Of course, this is only a short and highly selective list of three readily identifiable risks to PPACA; other known and unknown risks will emerge (or not) over time.

Finally, PPACA's flawed implementation poses risks to the reputation of the regulatory state as a whole. ${ }^{245}$ If PPACA fails to meet its publicly announced goals, the decline in public confidence is likely to be generalized, and will affect the functioning of the government well beyond the PPACA and health care.

\section{Implications for Administrative Law}

To this point, we have focused on describing our analytical framework, and applying it to the CFPB and the PPACA. In this section, we briefly note the implications of our analysis for administrative law. More specifically, do our findings have any implications for the endless debates over Chevron/Mead/Skidmore deference? In our view, if the basis for deference

insurance premiums.") See also Juliet Eilperen, White House delayed enacting rules ahead of 2012 election to avoid controversy, Wash. Post, Dec. 14, 2013.

${ }^{244}$ Shear \& Stolberg, supra note 218.

${ }^{245}$ Lawrence Summers, Lessons from reform, Wash. Post, Nov. 11, 2013, at A29 ("Even if the goal of getting the health-insurance exchanges working by Nov. 30 is achieved - and objective observers cannot regard this as a certainty - a shadow has been cast on the federal government's competence."); David Brooks, The Legitimacy Problem, N.Y. Times, Dec. 23, 2013 ("Over the next few years, the implementation will either go more smoothly and build faith in federal competence or go as it has been and destroy it.") 
is expertise, then the details of agency design should matter in deciding whether an agency is, in fact entitled to deference. Indeed, even if the stated basis for deference is democratic legitimacy (i.e., Congress delegated a task to the agency, and the court is required to defer to that delegation), that only moves the inquiry one level down - since the primary reason for Congress to have delegated an issue to a particular agency is because of its expertise. $^{246}$

To be sure, tying the degree of deference to the ever-changing details of agency design makes the doctrine even less predictable than it is already. ${ }^{247}$ But, if the justification for deference is expertise, it is hard to understand why one would ignore the question of whether the agency, in fact, has such expertise. ${ }^{248}$

\section{Conclusion}

In previous work, we identified seven factors that we believe are helpful in determining whether the combination of particular functions and/or goals within a single government agency or department is likely to work out well or poorly. When we apply these seven factors to the CFPB, we find that it scores well on several factors, but exceedingly poorly on others. It remains to be seen how things will play out, but our analysis suggests future difficulties are likely. Our brief discussion of the implementation difficulties with PPACA suggests similar dynamics are likely to dog health reform going forward.

In Washington, it has long been a truism that "personnel are policy." We believe that it is equally (if not more) a truism that "placement is policy." Where an agency is located, and what its street-level operators do on a day-to-day basis has a profound influence on the policies that will result. Time and again, one finds that the culture of a department, bureau, agency, and commission has a disproportionate impact, irrespective of the politics of the person who happens to be temporarily residing at 1600 Pennsylvania Avenue.

Former Secretary of Health, Education and Welfare Joseph Califano candidly admitted that when he served in the Johnson White House, "often

\footnotetext{
${ }^{246}$ Of course, there can be other reasons for delegation, such as the desire by Congress to be seen as "doing something" about a problem. Such "bubble laws" often have unintended consequences. See Larry Ribstein, Bubble Laws, 40 Houston L. Rev. 77 (2003)

${ }^{247}$ That said, there may be benefits in making the doctrine less predictable. See Jud Matthews, Deference Lotteries, 91 TEX. L. REV. (forthcoming, 2013)

${ }^{248}$ See Cohen, Cuéllar \& Weingast, supra note 61 . Courts must already face this issue, when deciding whether to give deference when two agencies share authority, but only one agency has been heard on the subject. See Gersen, Designing Agencies, supra note note 52, at 353-357.
} 
we didn't know where to put a program. . . and we didn't particularly care where it went; we just wanted to make sure it got enacted."249 For too long, legal scholars have taken an equally casual attitude toward the issue of agency design, and instead focused on case studies of individual agencies and the "greatest hits" of administrative law (e.g., delegation of powers, judicial review of agency actions, and the procedural requirements of administrative rulemaking and adjudication). Every taxi driver in Washington D.C. may know that "government organization has serious implications for policy outcomes," but the majority of legal scholarship on the administrative state demonstrates little attention to this simple point. ${ }^{250}$

Stated bluntly, agency design has long been the Rodney Dangerfield of administrative law: it gets no respect. ${ }^{251}$ We think it is time for the issue of agency design to command greater attention - particularly from those who find fault with our analytical framework, or have a more optimistic spin on the CFPB and the implementation of PPACA. Who does what matters - and sometimes it matters more than everything else combined.

${ }^{249}$ Timothy B. Clark, The Power Vacuum Outside the Oval Office, NATIONAL J. Feb. 24, 1979.

${ }^{250}$ For the exceptions, see supra notes 53-64, and accompanying text.

${ }^{251}$ See Lewis, supra note 65, at I ("Not many people find the study of American bureaucracy a provocative or compelling subject") 